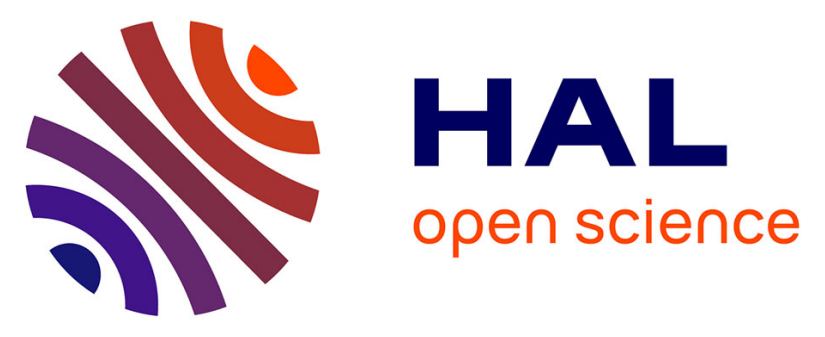

\title{
Calibrating an evapotranspiration model using radiometric surface temperature, vegetation cover fraction and near-surface soil moisture data
}

Bouchra Ait Hssaine, Olivier Merlin, Zoubair Rafi, Jamal Ezzahar, Lionel Jarlan, Saïd Khabba, Salah Er-Raki

\section{To cite this version:}

Bouchra Ait Hssaine, Olivier Merlin, Zoubair Rafi, Jamal Ezzahar, Lionel Jarlan, et al.. Calibrating an evapotranspiration model using radiometric surface temperature, vegetation cover fraction and near-surface soil moisture data. Agricultural and Forest Meteorology, 2018, 256-257, pp.104-115. 10.1016/j.agrformet.2018.02.033 . hal-01924705

\section{HAL Id: hal-01924705 https://hal.science/hal-01924705}

Submitted on 16 Nov 2018

HAL is a multi-disciplinary open access archive for the deposit and dissemination of scientific research documents, whether they are published or not. The documents may come from teaching and research institutions in France or abroad, or from public or private research centers.
L'archive ouverte pluridisciplinaire HAL, est destinée au dépôt et à la diffusion de documents scientifiques de niveau recherche, publiés ou non, émanant des établissements d'enseignement et de recherche français ou étrangers, des laboratoires publics ou privés. 


\title{
Calibrating an evapotranspiration model using radiometric surface temperature, vegetation cover fraction and near-surface soil moisture data
}

\author{
Bouchra Ait Hssaine ${ }^{1,2}$, Olivier Merlin ${ }^{1,2}$, Zoubair Rafi ${ }^{1}$, Jamal Ezzahar ${ }^{3}$, Lionel \\ Jarlan $^{1,2}$, Saïd Khabba ${ }^{1}$, Salah Er-Raki ${ }^{1}$ \\ ${ }^{1}$ Université Cadi Ayyad, Marrakech, Morocco \\ ${ }^{2}$ CESBIO, Université de Toulouse, IRD/CNRS/UPS/CNES, Toulouse, France \\ ${ }^{3}$ Equipe de Mathématiques et traitement de l'information (MTI), Ecole Nationale des \\ Sciences Appliquées, Université Cadi Ayyad, Safi, Morocco \\ Corresponding author: Bouchra Ait Hssaine (bouchraaithssaine@gmail.com)
}

Key Points:

- TSEB model is enhanced to TSEB-SM model by using surface biophysical characteristics

- Calibration method is developed to retrieve parameters affecting evapotranspiration

- The performance of TSEB and TSEB-SM models is evaluated over irrigated wheat fields

- The Priestley-Taylor coefficient is found to vary in time as a function of soil moisture

\begin{abstract}
An accurate representation of the partitioning between soil evaporation and plant transpiration is an asset for modeling crop evapotranspiration (ET) along the agricultural season. The TwoSurface energy Balance (TSEB) model operates the ET partitioning by using the land surface temperature (LST), vegetation cover fraction (fc), and the Priestley Taylor (PT) assumption that relates transpiration to net radiation via a fixed PT coefficient ( $\left.\alpha_{\mathrm{PT}}\right)$. To help constrain the evaporation/transpiration partition of TSEB, a new model (named TSEB-SM) is developed by using, in addition to LST and fc data, the near-surface soil moisture (SM) as an extra constraint on soil evaporation. An innovative calibration procedure is proposed to retrieve three key parameters: $\alpha_{\mathrm{PT}}$ and the parameters $\left(\mathrm{a}_{\mathrm{rss}}\right.$ and $\mathrm{b}_{\mathrm{rss}}$ ) of a soil resistance formulation. Specifically, $a_{\text {rss }}$ and $b_{\text {rss }}$ are retrieved at the seasonal time scale from SM and LST data with $\mathrm{f}_{c}<0.5$, while $\alpha_{\text {PT }}$ is retrieved at the daily time scale from SM and LST data for $f_{c}>0.5$. The new ET model named TSEB-SM is tested over 1 flood- and 2 drip-irrigated wheat fields using in situ data collected during two field experiments in 2002-2003 and 2016-2017. The calibration algorithm is found to be remarkably stable as $\alpha_{\mathrm{PT}}, a_{\mathrm{rss}}$ and $b_{\text {rss }}$ parameters converge rapidly in few (2-3) iterations. Retrieved values of $\alpha_{\mathrm{PT}}$, $\mathrm{a}_{\mathrm{rss}}$ and $b_{\mathrm{rss}}$ are in the range 0.0-1.4, 5.7-9.5, and 1.4-6.9, respectively. Calibrated daily $\alpha_{\text {PT }}$ mainly follows the phenology of winter wheat crop with a maximum value coincident with the full development of green biomass and a minimum value reached at harvest. The temporal variations of $\alpha_{\mathrm{PT}}$ before senescence are attributed to the dynamics of both root-zone soil moisture and the amount of green biomass (vegetation water
\end{abstract}


content). Moreover, the overall (for the three sites) root mean square difference between the ET simulated by TSEB-SM and eddy-covariance measurements is $67 \mathrm{~W} \mathrm{~m}^{-2}$ (24\% relative error), compared to $108 \mathrm{~W} \mathrm{~m}^{-2}$ (38\% relative error) for the original version of TSEB using default parameterization $\left(\alpha_{\mathrm{PT}}=1.26\right)$. Such a calibration strategy has great potential for applications at multiple scales using remote sensing data including thermal-derived LST, solar reflectance-derived $\mathrm{f}_{\mathrm{c}}$ and microwave-derived SM.

\section{Introduction}

A large variety of evapotranspiration (ET) models and measurements have been reported in the literature (Allen et al., 2011). However, ET estimation over extended areas including different biomes and climates is still subject to significant uncertainties (Pereira et al., 2004; Ershadi et al., 2014). Although the main drivers of ET, such as atmospheric evaporative demand, vegetation type, development stages and health, surface biophysical characteristics and soil water availability (e.g. Federer et al., 2003), are now well identified, one major difficulty in modeling this process lies in a lack of relevant input data available at the desired space and time scales (Allen et al., 2011; Pereira et al., 2014). The accuracy of ET estimates at a given scale thus currently represents a trade-off between model complexity and realism, which is usually related to i) the number of model parameters and forcing variables and ii) the availability of data that generally decreases with the spatial extent (Allen et al., 2011; Gharsallah et al., 2014).

Regarding data availability over large areas and at multiple scales, remote sensing observations provide very relevant information to feed ET models such as vegetation indices, land surface temperature (LST) and near-surface soil moisture (SM). Especially, SM is one of the main controlling factors of soil evaporation (e.g. Chanzy et al. 1993), vegetation cover fraction $\left(f_{c}\right)$ provides an essential structural constraint on evaporation/transpiration partitioning (e.g. Allen et al. 2000) and LST is a signature of available energy and evapotranspiration (e.g. Norman et al. 1995). For this reason, efforts have been made to integrate those data as additional and complementary information on ET (e.g. Price et al., 1990). Through its link with ET under moisture-limited conditions, LST has been extensively used to retrieve ET at a wide range of spatial resolutions (Kalma et al., 2008). LST-based ET retrieval methods are generally classified in two categories. The first one is the so-called "residual" method, which estimates latent heat flux as a residual term of the surface energy balance (e.g. Norman et al., 1995; Su, 2002). The second one is named the "contextual" method based on the interpretation of the LST versus vegetation index feature space (e.g. Moran et al., 1994 ; Long and Singh, 2012), the interpretation of the LST versus albedo feature space (e.g. Roerink et al., 2000), or the interpretation of both spaces (Merlin 2013; Merlin et al., 2014). The use of SM data, Jung et al. (2010) related the global ET trend to the SM trend derived from TRMM (Tropical Rainfall Monitoring Mission) microwave data. At regional scale, ET was found to have a correlation of about 0.5 with the SM derived from airborne L-band data and a correlation even larger for $\mathrm{f}_{\mathrm{c}}$ values lower than 0.5 (Bindlish et al., 2001; Diarra et al., 2017). This was the basis for developing ET models based on microwave-derived SM data (Kustas et al., 1998; Bindlish et al., 2001; Kustas et al., 2003; Li et al., 2006; Gokmen et al., 2012; Li et al., 2015).

Among a wide panel of existing ET models, the Priestley Taylor (PT) assumption that empirically relates ET to net radiation (Priestley and Taylor 1972) has shown a growing interest (Norman et al., 1995, Kustas and Norman 1999, Li et al., 2005, Anderson et al., 2007, Fisher et al., 2008, Agam et al., 2010, Jin et al., 2011, Yao et al., 2015, Ai et al., 2016). PT coefficient noted $\alpha_{\mathrm{PT}}$ directly relates latent heat flux to the energy available at the surface. Since neglecting the aerodynamic resistance term included in the full Penman-Monteith equation (Monteith 1965), the PT formulation is relatively simple, requires less input data and has proven to be 
remarkably accurate and robust for estimating potential ET in a wide range of conditions (Fisher et al., 2008). It is therefore well suited for operational (McAneney et al., 1996) and large scale (Anderson et al., 2008) applications. In addition, recent studies based on in situ global data sets have reported a good robustness of the PT modeling approach over a variety of biomes (Ershadi et al., 2014). Nevertheless, various theoretical (e.g. De Bruin, 1983) and experimental (e.g. Fisher et al., 2008) studies have stressed that the PT coefficient is variable under different surface and atmospheric conditions. In a literature review, the factors that influence the variability of $\alpha_{\text {PT }}$ are: leaf area index (Fisher et al., 2008; Jin et al., 2011; Ai and Yang, 2016), the green fraction of canopy (Norman et al., 1995; Fisher et al., 2008), soil water availability (Davies and Allen, 1973; Mukammal and Neumann 1977; De Bruin, 1983; Eichinger et al., 1996; Fisher et al., 2008; Jin et al., 2011; Perez et al., 2017; Yao et al., 2017), vapor pressure deficit or advective conditions (Jury and Tanner, 1975; Kustas et al., 2000; Agam et al., 2010; Colaizzi et al., 2014), wind speed (Mukammal and Neumann, 1977), air temperature (Ai and Yang, 2016), air relative humidity (Er-Raki et al., 2010), plant temperature (Fisher et al., 2008), surface sensible heat flux (Pereira and Nova 1992) and mulch fraction (Ai and Yang, 2016). As a result of changes in the above ecophysiological and environmental constraints, $\alpha_{\mathrm{PT}}$ commonly varies in the range $0.5-2.0$ with an average value estimated around 1.3 (above references).

Data available from space can help in implementing the PT approach from three distinct perspectives: i) applying a constraint on vegetation transpiration using an a priori value for $\alpha_{\mathrm{PT}}$ (Norman et al., 1995; Kustas et al., 1999; Anderson et al., 2008), ii) applying a constraint on soil evaporation using SM data (Bindlish et al., 2001; Yao et al., 2017), or iii) retrieving the PT coefficient from vegetation indices (Fisher et al., 2008; Jin et al., 2011; Yao et al., 2015; Yao et al., 2017) or from an interpretation of the LST-vegetation index feature space (Jiang and Islam, 2001; Wang et al., 2006; Perez et al., 2017). While LST, vegetation indices and SM are alternatively used by satellite-based PT approaches, few studies have combined all three data types. In fact, most studies have compared LST-based versus SM-based ET models separately (Kustas et al., 1998; Kustas et al., 2003; Li et al., 2006; Gokmen et al., 2012). Given that SM controls the soil temperature (via the soil evaporation) and that LST integrates both soil and vegetation temperatures, the main issue to integrate simultaneously SM and LST into an unique model is to ensure a robust convergence of soil/vegetation temperatures (Kustas et al., 2003; Li et al., 2006) and associated evaporation/transpiration fluxes. The recent studies of Li et al.(2015) and Song et al.(2016) combined LST and SM to better constrain ET but both approaches relied on a priori reduction coefficients of potential ET. Reduction coefficients of potential ET are equivalent to the soil evaporative efficiency (defined as the ratio of actual to potential evaporation, e.g. Merlin et al., 2016) and to the vegetation stress functions (defined as the ratio of actual to potential transpiration, e.g. Hain et al., 2009) for the soil and vegetation component, respectively. The point is there is no universal parameterization of both soil evaporation efficiency and vegetation stress functions. Alternatively, Sun et al. (2012) proposed an innovative assimilation method to calibrate the parameters of a SVAT (Soil Vegetation Atmosphere Transfer) model from available remote sensing variables including LST and SM. Assimilation results improved ET estimates but the retrieved parameters were mostly conceptual due to the simplicity of the surface model used.

In this context, the objective of this paper is: (i) the modification of the PT-based TSEB formalism (Norman et al., 1995; Kustas et al., 1999) to integrate LST and SM in situ data simultaneously (the modified version is named TSEB-SM), and (ii) the development of a calibration procedure of TSEB-SM to retrieve the main parameters of soil evaporation (soil resistance) and plant transpiration $\left(\alpha_{\mathrm{PT}}\right)$. The approach is tested over three irrigated wheat crops in the Tensift basin, central Morocco. In each case, the calibration procedure is tested and the 
139 TSEB-SM latent and sensible heat fluxes are evaluated and compared against the original 140 TSEB simulations.

\section{Methods}

\section{$142 \quad 2.1 \quad$ Data}

\section{$143 \quad$ 2.1.1 Sites description}

The study sites are located in irrigated agricultural areas east (R3 perimeter) and west climate in the region is semi-arid, with an average yearly precipitation in the order of $250 \mathrm{~mm}$, of which approximately $75 \%$ falls during the winter and spring (November-April). The average humidity of the atmosphere is $50 \%$ and the reference crop ET is estimated as $1600 \mathrm{~mm}$ per year (Allen et al., 1998), greatly exceeding the annual rainfall.

Two data sets are used herein. The first data set was collected from December 2002 to May 2003 over a wheat crop in the R3 zone. The second one was collected from November 2016 to May 2017 over two wheat crops near Chichaoua. Those experiments were carried out to monitor the energy and water balance as well as the soil and vegetation characteristics and conditions during the entire wheat growing cycle. The R3 crop field is 4 ha and is irrigated through periodic (approximately every 3 weeks) flooding with a mean quantity of $30 \mathrm{~mm}$ regardless of precipitation. Both Chichaoua crop fields are 1.5 ha and are irrigated by drip technique. During the 2016-17 experiment, one (reference) field was irrigated according to the crop water needs estimated by the FAO method every 3 to 4 days until mid-April while the other (controlled) field was irrigated exactly the same way except during controlled stress periods when irrigation was cut. The mean irrigation quantity was about $15 \mathrm{~mm}$ for both crop fields, whereas the total water supply by drip irrigation was 374 and $504 \mathrm{~mm}$ for the controlled and reference field, respectively. 


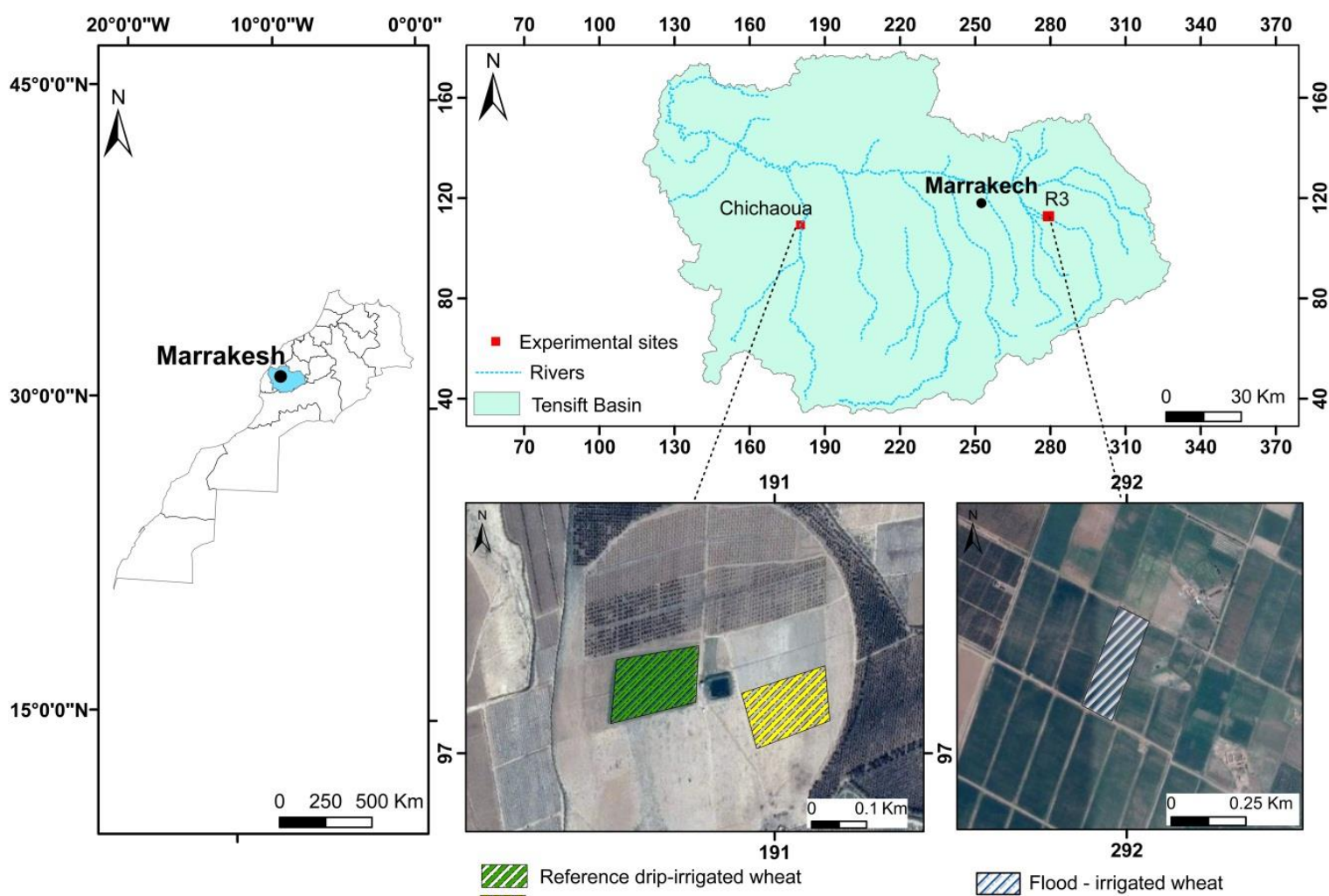

Figure 1.Location of the three study sites including a flood-irrigated wheat crop in the R3 zone (east of Marrakech) and two (controlled and reference) drip-irrigated wheat crops near Chichaoua city (west of Marrakech) in the Tensift basin, central Morocco.(Flat area)

\subsubsection{Surface fluxes}

An eddy covariance (EC) tower was installed over each field to measure the latent (LE) heat and sensible $(\mathrm{H})$ heat fluxes at a 2-m height. EC systems included a CSAT3 3D sonic anemometer (Campbell scientific Ltd, Logan USA) over the three sites, a LICOR-7500 openpath infrared gas analyzer (Campbell scientific Ltd, Logan USA) installed over the R3 site and a KH20 Krypton hygrometer (Campbell Scientific Ltd, Logan USA) installed over both Chichaoua sites. The half-hourly fluxes were calculated off-line using the EC processing software 'ECpack', after performing all required corrections for planar fit correction, humidity and oxygen (KH20), frequency response for slow apparatus, and path length integration (Van Dijk et al., 2004). EC towers were also equipped with Kipp and Zonen CNR radiometers to measure net radiation ( $\mathrm{Rn}$ ) and heat flux plates (Campbell Scientific Ltd, Logan USA) to measure the soil heat flux $(G)$. Analysis of the energy balance closure showed that the sum of latent and sensible heat flux measured independently by the EC systems was often lower than the available energy (Rn-G). The relative closure was satisfied by about $88 \%, 64 \%$ and $70 \%$ (of available energy) for the R3, controlled and reference sites, respectively. This problem could not be explained neither by the mismatch in the spatial extent of flux measurements, nor by the uncertainties associated with the measurements of soil heat flux and net radiation (Twine et al., 2000, Ezzahar et al. 2009, Hoedjes 2008). Correction was hence performed using the approach suggested by Twine et al. (2000). The energy budget closure was forced at the 30 min time step using the daily Bowen ratio (called $\beta=\mathrm{H} / \mathrm{LE}$ ). Corrected turbulent fluxes were 
derived as $L E=\frac{\beta}{\beta+1}(R n-G)$ and $H=\frac{(R n-G)}{\beta+1}$, with $\beta$ computed from the 30-min observed $\mathrm{H}$ and LE cumulated between 9 am and $5 \mathrm{pm}$. The Bowen ratio correction enhanced these turbulent fluxes by about 21, 39 and $50 \%$ for $\mathrm{H}$ and 20, 42 and 56\% for LE, for R3 zone, controlled and reference sites, respectively.

\subsubsection{Land surface temperature, soil moisture and vegetation cover fraction}

Surface temperature was measured by using an infrared thermometer (IRTS-P) set up at a 2-m height above ground. Two sensors, oriented downwards, were used in each field. The measured LST is taken as the arithmetical mean of the two independent measurements.

Time Domain Reflectometry (TDR) probes (model CS615, CS655) were installed in a soil pit near the EC towers to measure soil water content at different soil depths of 5, 10, 20, 30, 50, $100 \mathrm{~cm}$ and 5, 15, 25, 35, 50, $80 \mathrm{~cm}$ and 5, 15, 30, 50, $80 \mathrm{~cm}$ for the flood-, controlled dripand reference drip-irrigated wheat, respectively. The TDR technique is based on the measurement of the soil dielectric constant to estimate its volumetric water content. An appropriate calibration of the TDR measurement is necessary because several factors as the electrical conductivity, bulk density and soil texture can affect the soil dielectric constant (Topp et al., 1980; Regalado et al., 2001; Roth et al., 1992; Tomer et al., 1999; Weitz et al., 1997). The field volumetric moisture content was determined using the gravimetric method; three samples were collected at installation depth of each TDR probe using a $392.5 \mathrm{~cm}^{3}$ aluminum core. A linear regression was established between the volumetric water content and the square root of the TDR time response ( $\tau$ in s) $\left(S M=a_{T D R} * \sqrt{\tau}+b_{T D R}\right)$.

The vegetation cover fraction -defined as the vegetated surface area projected on the ground at nadir, per soil surface area unit- was measured routinely within each field using a digital photography-based method. Hemispherical photographs were taken at various representative points of the field using a Nikon CoolPix camera equipped with a fisheye lens. This method binarizes digital photos, in vegetation and soil, based on thresholds in the green and red bands (Khabba et al., 2009).

\subsection{Models and calibration strategies}

In this section, the main equations of the original version of TSEB model (Norman et al., 1995; Kustas et al., 1999) are briefly reproduced and the new TSEB-SM model is fully described. Note that the main difference between the two models concerns the treatment of soil evaporation, which is either estimated as a residual term for TSEB or explicitly represented through a soil resistance term for TSEB-SM.

\subsubsection{Models}

\section{A. TSEB model}

The TSEB model was presented and described by Norman et al., (1995), Norman et al. (2000), Kustas and Norman (1999), Timmermans et al (2007), French et al. (2015) and Colaizzi et al. (2012). It produces two separate energy balances for the soil and vegetation and estimates evaporation and transpiration as residual term of the energy balance. Two variables derived from remote sensing instruments are key inputs for TSEB model: The first is the surface temperature, which is used to estimate the sensible heat flux and the second is the fraction cover, which controls the energy partitioning between surface vegetation and soil. 
The PT coefficient $\left(\alpha_{\mathrm{PT}}\right)$ is one of the most sensitive parameters of TSEB, because it drives the vegetation latent heat flux. Most studies conducted with TSEB have used its generic value around 1.3 (Norman et al., 1995; Kustas and Norman, 1999; Bindlish et al., 2001; Anderson et al., 2007; Colaizzi et al., 2014). Other studies have identified different values of $\alpha_{\mathrm{PT}}$ depending on the vegetation cover fraction and particular forcing conditions. Notably, the PT coefficient was found to be smaller for dry surfaces and higher for humid conditions (Eichinger et al., 1996). Nevertheless the relative stability of $\alpha_{\mathrm{PT}}$ in many conditions has led to set $\alpha_{\mathrm{PT}}$ constant. Consistent with this assumption, $\alpha_{\mathrm{PT}}$ is set to 1.26 in TSEB (Priestley and Taylor, 1972).

\section{B. TSEB-SM model}

The TSEB formalism is modified to integrate SM as an additional constraint on modeled ET. In practice, the energy balance for vegetation and soil in TSEB-SM is the same as in TSEB, but the soil evaporation is now explicitly represented as a function of SM via a soil resistance term. Note that Song et al. (2016) have recently introduced SM in TSEB using a formulation of soil evaporative efficiency. While there is partial equivalence between both formulations, the soil resistance formulation is preferred herein as its parameters can be calibrated either from soil texture information (Merlin et al., 2016) or from a combination of LST and SM data under bare soil conditions (Merlin et al., 2017).

The soil latent heat flux is estimated as:

$$
\mathrm{LE}_{\text {soil }}=\frac{\rho \mathrm{c}_{\mathrm{p}}}{\gamma} \cdot \frac{\left(\mathrm{e}_{\mathrm{s}}-\mathrm{e}_{\mathrm{a}}\right)}{\mathrm{r}_{\mathrm{ah}}+\mathrm{r}_{\mathrm{s}}+\mathrm{r}_{\mathrm{ss}}}
$$

where $e_{s}$ is the saturated vapor pressure at the soil surface, $e_{a}$ is the air vapor pressure, and $r_{s s}$ is the resistance to vapor diffusion in the soil. $r_{\mathrm{ss}}$ is expressed as follows (Passerat de Silans, 1986) :

$$
\mathrm{r}_{\mathrm{ss}}=\exp \left(\mathrm{a}_{\mathrm{rss}}-\mathrm{b}_{\mathrm{rss}} * \frac{\mathrm{SM}}{\mathrm{SM}_{\mathrm{sat}}}\right)
$$

with SM being the soil moisture in the $0-5 \mathrm{~cm}$ soil layer, $\mathrm{a}_{\mathrm{rss}}$ and $\mathrm{b}_{\mathrm{rss}}$ are two empirical parameters and $\mathrm{SM}_{\text {sat }}$ the soil moisture at saturation expressed as:

$$
\mathrm{SM}_{\text {sat }}=0.1 *\left(-108 * \mathrm{f}_{\text {sand }}+49.305\right)
$$

with $\mathrm{f}_{\text {sand }}$ is the percentage of sand in the soil.

The flowchart of Figure 2 summarizes the different steps followed to resolve the energy balance in TSEB-SM model. The algorithm is based on an iterative procedure that loops on the MoninObukhov length (MO length), which is a scale parameter that characterizes the degree of instability or stability of the boundary layer. MO length is approximately the height at which aerodynamic shear, or mechanical energy, is equal to the buoyancy energy. In practice, MO length is used as correction factor to determine the aerodynamic resistance $r_{a h}$. First, the algorithm starts by initializing the soil and vegetation temperatures, as well as sensible and latent heat fluxes. Then it calculates the available energy for the soil-vegetation-atmosphere interface by estimating the surface net radiation and its partition between the vegetation and the soil, as well as the soil heat flux. The way soil and vegetation temperatures are estimated is in fact a specificity of the new model, which is based on the explicit resolution of the energy balance for soil and vegetation respectively. Component temperatures are obtained by minimizing cost functions $\mathrm{F}_{\text {soil }}$ and $\mathrm{F}_{\mathrm{veg}}$ :

$$
F_{\text {soil,k }}=\left(R_{n, \text { soil, } \mathrm{k}}-H_{\text {soil, } \mathrm{k}}-L_{\text {soil, } \mathrm{k}}-\mathrm{G}_{\mathrm{k}}\right)^{2}
$$




$$
\mathrm{F}_{\mathrm{veg}, \mathrm{k}}=\left(\mathrm{R}_{\mathrm{n}, \mathrm{veg}, \mathrm{k}}-\mathrm{H}_{\mathrm{veg}, \mathrm{k}}-\mathrm{LE}_{\mathrm{veg}, \mathrm{k}}\right)^{2}
$$

271 with $\mathrm{k}$ being a loop index. By using the formula of the Newton method:

$$
\mathrm{T}_{\text {soil }, \mathrm{k}+1}=\mathrm{T}_{\text {soil,k }}-\frac{\mathrm{F}_{\text {soil }_{\mathrm{k}}}}{\mathrm{dF}_{\text {soil }_{\mathrm{k}}}}
$$

272

$$
\mathrm{T}_{\mathrm{veg}, \mathrm{k}+1}=\mathrm{T}_{\mathrm{veg}, \mathrm{k}}-\frac{\mathrm{F}_{\mathrm{veg}_{\mathrm{k}}}}{\mathrm{dF}_{\mathrm{veg}_{\mathrm{k}}}}
$$

273 where $\mathrm{dF}_{\text {soil }}$ and $\mathrm{dF}_{\text {veg }}$ are the first derivative of the cost function for soil and vegetation, 274 respectively.

275 At the end of each iteration, the simulated LST (noted $\mathrm{T}_{\text {surf,sim }}$ Figure 2 ) and heat fluxes are 276 used to recalculate the MO length iteratively. The iterative procedure is repeated until MO 277 length (and H) converges, meaning that the difference between two successive values is smaller 278 than a given threshold (numerical uncertainty). 


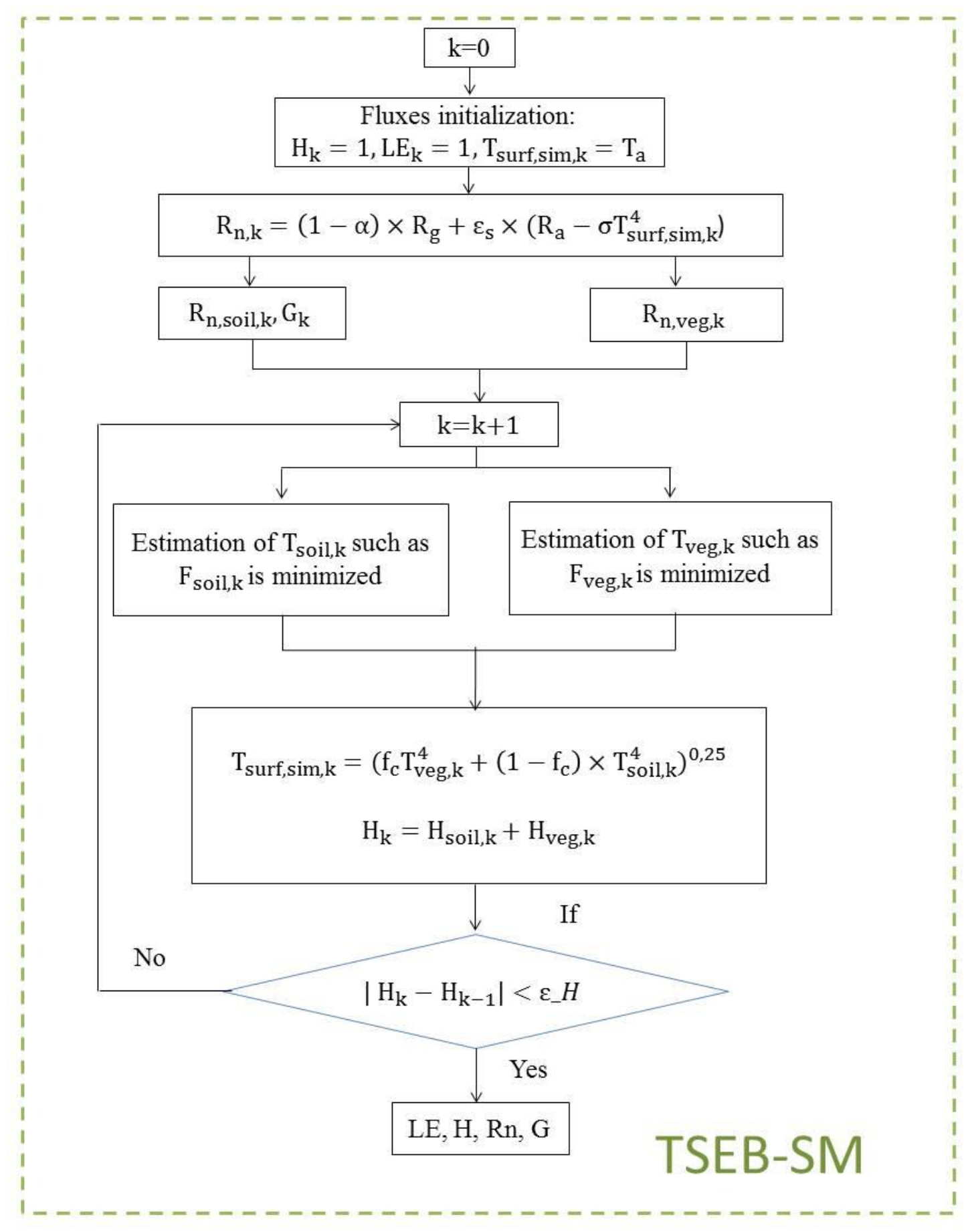

Figure 2.Schematic diagram of TSEB-SM model.

\subsubsection{Calibration strategies}

The calibration approach of TSEB-SM is presented below. In this case, the calibration strategy is tightly coupled to the model formalism and the availability of input data (LST in the former case and both LST and SM in the latter). 


\section{TSEB-SM}

The calibration procedure of TSEB-SM is presented in the schematic diagram of Figure 3. It is done in two steps: the first aims to provide first guess estimates of $a_{\text {rss }}$ and $b_{\text {rss }}$ (named $a_{\text {rss,FG }}$ and $b_{\text {rss,FG }}$ ) as input to the second step that aims to provide the final values of ( $a_{\text {rss,cal }}$, $b_{\text {rss,cal }}$ and $\alpha_{\mathrm{PT}, \text { cal,daily. }}$

Given that soil evaporation and plant transpiration may compensate each other to result in similar total ET values, it is important to ensure that the calibration procedure is well defined, meaning that a unique triplet ( $\left.a_{\text {rss }}, b_{\text {rss, }}, \alpha_{\mathrm{PT}}\right)$ is systematically obtained at the desired time scale. In order to do so, the calibration data set is divided into two regions with specific behaviors: i) data with $\mathrm{f}_{\mathrm{c}} \leq 0.5$ for which ET is mainly controlled by soil evaporation and ii) data with $\mathrm{f}_{\mathrm{c}}>$ 0.5 for which ET is dominated by plant transpiration. In both data sets, soil evaporation and plant transpiration may occur simultaneously but the LST over the mixed surface is expected to be more sensitive to soil evaporation and plant transpiration for $\mathrm{f}_{\mathrm{c}} \leq 0.5$ and $\mathrm{f}_{\mathrm{c}}>0.5$, respectively (Moran et al. 1994; Merlin et al. 2012).

The first calibration step initializes $\alpha_{\mathrm{PT}}=1.26$ and inverts $\mathrm{r}_{\mathrm{SS}}$ at each time (30-min) step for data with $\mathrm{f}_{\mathrm{c}} \leq 0.5$. The $\mathrm{r}_{\mathrm{ss}}$ is first adjusted to minimize the following cost function:

$$
\mathrm{F}_{\text {inst }}=\left(\mathrm{T}_{\text {surf,sim }}-\mathrm{T}_{\text {surf,mes }}\right)^{2}
$$

using the Newton method:

$$
r_{\mathrm{ss}, \mathrm{k}+1}=\mathrm{r}_{\mathrm{ss}, \mathrm{k}}-\frac{\mathrm{F}_{\text {inst }_{\mathrm{k}}}}{\mathrm{dF}_{\text {inst }_{\mathrm{k}}}}
$$

where $\mathrm{T}_{\text {surf,sim }}$ and $\mathrm{T}_{\text {surf,mes }}$ are the LST simulated by TSEB-SM model and observed over the crop field at the 30-min time step, respectively. The inverted $r_{s s}$ is then correlated to the observed SM to estimate $a_{r s s}$ and $b_{\text {rss. }}$ In practice, $a_{\text {rss }}$ and $-b_{\text {rss }} / S_{\text {sat }}$ are the intercept and the slope of the linear regression of the $\ln \left(\mathrm{r}_{\mathrm{ss}}\right)$ versus SM relationship (see Equation 2). As the retrieved pair ( $a_{\mathrm{rss}}, b_{\mathrm{rss}}$ ) depends on the $\alpha_{\mathrm{PT}}$ value, an iterative loop is run on $\mathrm{a}_{\mathrm{rss}}, b_{\mathrm{rss}}$ and $\alpha_{\mathrm{PT}}$ until convergence of $a_{r s s}$ and $b_{\text {rss }}$ is achieved. At each iteration, the inverted $a_{\text {rss }}$ and $b_{\text {rss }}$ are used as input to invert $\alpha_{P T}$ for data with $\mathrm{f}_{\mathrm{c}}>0.5$. The PT Taylor coefficient is adjusted, at the daily time scale, to minimize the following cost function:

$$
\mathrm{F}_{\text {daily }}=\sum_{\mathrm{i}=1}^{\mathrm{N}}\left(\mathrm{T}_{\text {surf,sim, } \mathrm{i}}-\mathrm{T}_{\text {surf,mes }, \mathrm{i}}\right)^{2}
$$

with $\mathrm{N}$ being the number of 30-min LST measurements available for a given day. To keep a (time) scale consistency between all three retrieved parameters in calibration step 1, the daily inverted $\alpha_{\mathrm{PT}}$ is averaged at the seasonal time scale before being used as input to the following (next iteration) inversion of $a_{\text {rss }}$ and $b_{\text {rss }}$. To further assess the model's stability, the initial values of ( $\left.\mathrm{a}_{\mathrm{rss}, \mathrm{k}=0}, \mathrm{~b}_{\mathrm{rss}, \mathrm{k}=0}\right)$ were randomly set to a range of values between 1 and 13 and the results (not shown) confirmed the robustness of the calibration approach, regardless of the initialization.

The second calibration step refines the estimation of $\alpha_{\mathrm{PT}}$ at the daily scale. The first guess $\mathrm{a}_{\mathrm{rss}, \mathrm{FG}}$

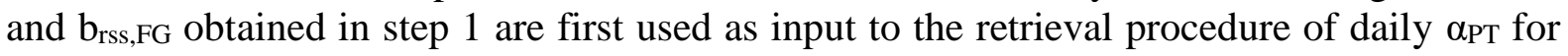
data with $\mathrm{f}_{\mathrm{c}}>0.5$ (minimization of $\mathrm{F}_{\text {daily }}$ ). Next, the daily retrieved $\alpha_{\mathrm{PT}}$ is smoothed to remove outliers as well as to reduce random uncertainties in daily retrieved $\alpha_{\mathrm{PT}}$. Then, the smoothed $\alpha_{\mathrm{PT}}$ is normalized between its minimum and maximum values reached during the agricultural season after having forced the minimum value of smoothed $\alpha_{\mathrm{PT}}$ to 0 at harvest so that transpiration is zero at this time: 


$$
\alpha_{\mathrm{PT}, \text { cal,daily }}=\frac{\alpha_{\mathrm{PT}, \text { daily }_{\text {smooth }}}-\min \left(\alpha_{\mathrm{PT}, \text { daily }_{\text {smooth }}}\right)}{\max \left(\alpha_{\mathrm{PT}, \text { daily }_{\text {smooth }}}\right)-\min \left(\alpha_{\mathrm{PT}, \text { daily }_{\text {smooth }}}\right)} * \max \left(\alpha_{\mathrm{PT}, \text { daily }} \text { smooth }_{\text {s. }}\right)
$$

Finally $r_{\mathrm{ss}}$ is calibrated a last time to ensure consistency between daily calibrated $\alpha_{\mathrm{PT}, \text { cal,daily }}$ and final $a_{\text {rss,cal }}$ and $b_{\text {rss,cal }}$ (see Figure 3).

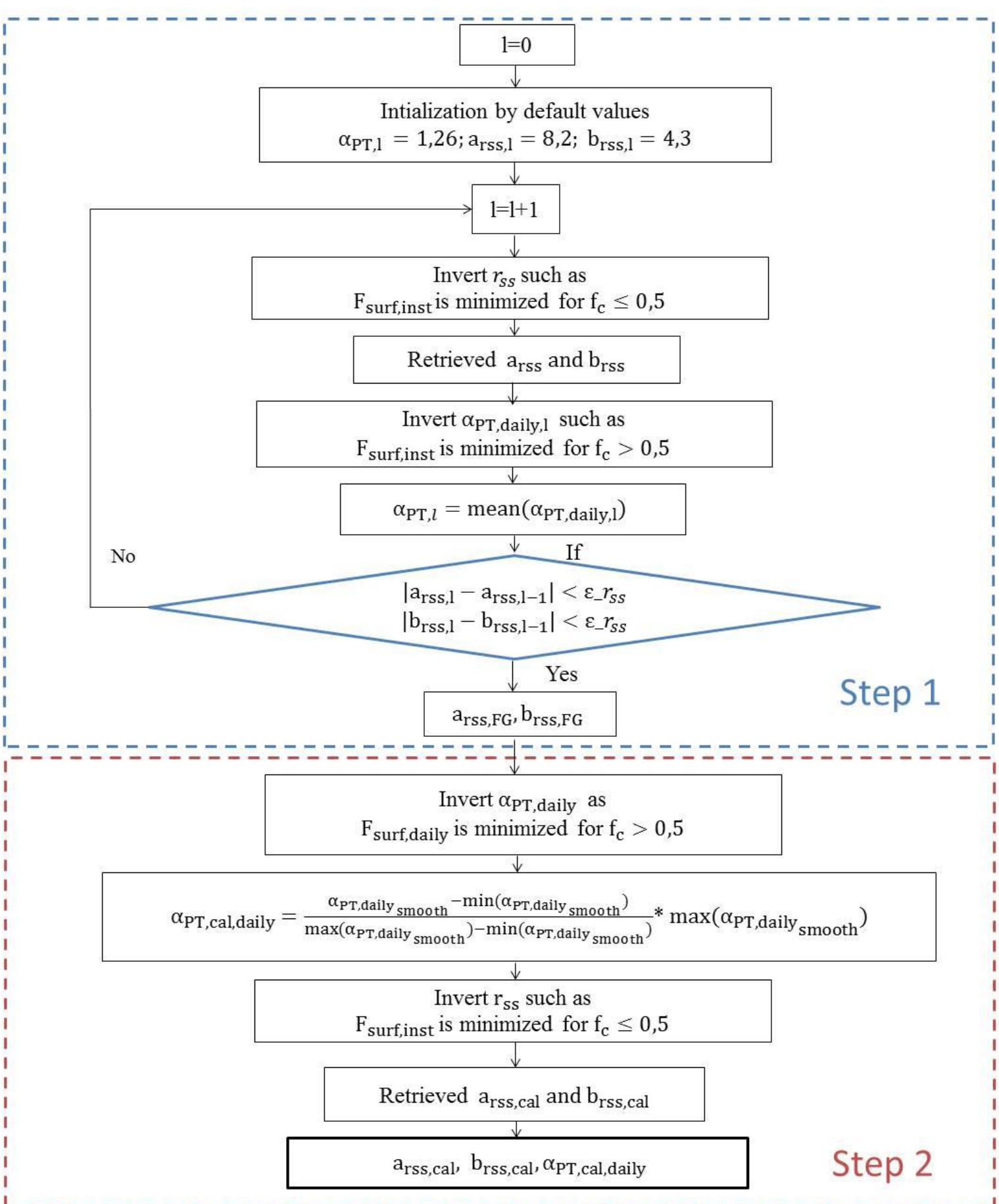




\section{Results and Discussions}

The proposed calibration of $r_{s s}$ and $\alpha_{\mathrm{PT}}$ is successively applied to the flood-irrigated (R3), the controlled drip-irrigated (Chichaoua) and the reference drip-irrigated (Chichaoua) wheat sites. The TSEB-SM approach is then assessed in terms of evapotranspiration. In practice, the $\mathrm{H}$ and LE simulated at the half hourly time scale (between $11 \mathrm{am}$ and 1:30 pm) by TSEB-SM and by the original TSEB model (using an a priori default value for $\alpha_{\mathrm{PT}}$ ) are compared against EC measurements at the three experimental sites.

\subsection{Retrieved parameters}

Figure 4 plots the iterative values of $a_{\text {rss }}, b_{\text {rss }}$ and mean $\alpha_{\mathrm{PT}}$ during calibration step 1. Iteration 0 corresponds to default values. The convergence of all three parameters is very fast, requiring only 2 or 3 iterations for achieving a relative error better than $1 \%$. This result confirms the appropriateness of separating the calibration range in $\mathrm{f}_{\mathrm{c}}$ intervals where one parameter has significantly more weight on simulation results (i.e. simulated LST and associated fluxes) than the others. The calibrated pair $\left(a_{r s s}, b_{r s s}\right)$ is $(5.67,1.40),(6.51,3.82)$ and $(9.47,6.87)$ for the flood-, controlled drip- and reference drip-irrigated field, respectively. The mean retrieved values $(7.2,4.0)$ are relatively close to those estimated in Sellers et al. (1992) (8.2, 4.3). The variability of $a_{\text {rss }}$ and $b_{\text {rss }}$ can be explained by numerous factors such as soil texture (Merlin et al., 2016) and meteorological conditions (Merlin et al., 2011). Nevertheless, retrieved parameters are significantly different for both drip sites whereas they i) are located about 200 $\mathrm{m}$ apart only and ii) have similar soil texture and meteorological conditions. In fact, retrieved $a_{\text {rss }}$ is an increasing function of retrieved $b_{\text {rss }}$ due to compensation effects between $a_{\text {rss }}$ and $b_{\text {rss }}$ for a given SM and LST observation pair and regardless of soil properties and meteorological conditions. Such compensation reveals the empirical nature of the $r_{s s}$ formulation in Sellers et al. (1992). 


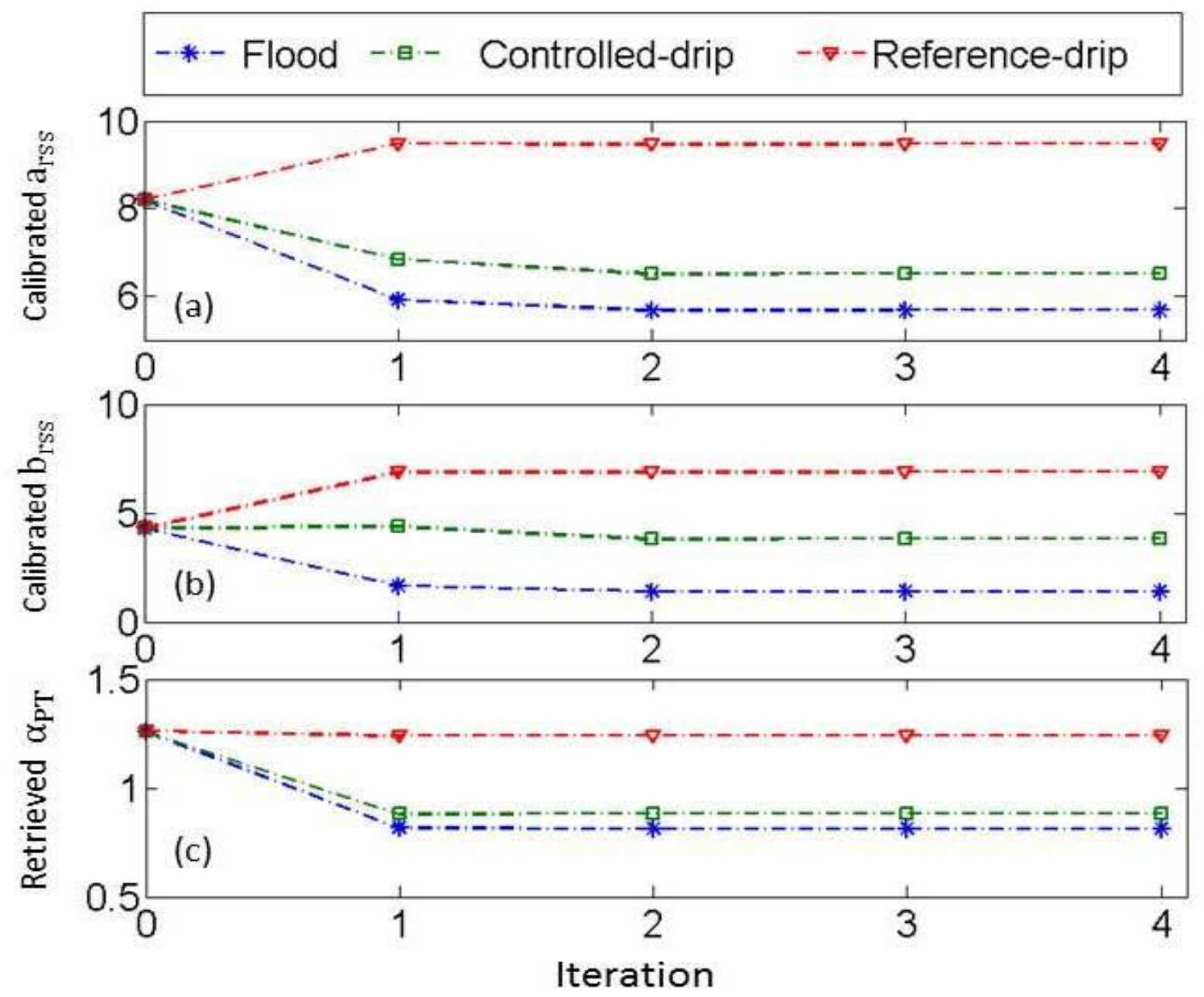

Figure 4.Iterative values of arss, (a), brss (b) and mean value of retrieved $\alpha_{P T}(c)$ for the flood-, controlled drip-and reference drip-irrigated wheat fields separately (calibration step 1).

The mean value of $\alpha_{\mathrm{PT}}$ at the semi-hourly time scale (see Figure 4) is $0.81,0.88$ and 1.24 for the flood-, controlled drip- and reference drip-irrigated wheat fields, respectively. Note that the mean value is very close to the theoretical $\alpha_{\mathrm{PT}}$ value for the reference drip-irrigated field case. It is suggested that $f_{g}$ generally equals 1 at the maximum of $\alpha_{\mathrm{PT}}$ (peak of ET), so that the maximum $\alpha_{\text {PT }}$ value is directly comparable to its default value (1.26) corresponding to fully unstressed conditions (Priestley and Taylor, 1972). Nonetheless, the mean $\alpha_{\mathrm{PT}}$ is significantly smaller than the default value for the flood- and controlled drip-irrigated cases. Lower values can be associated with stress conditions that may have occurred during the crop development.

Figure 5 plots the time series of daily retrieved $\alpha_{\mathrm{PT}}$ for each site separately. It can be seen that the maximum value of daily $\alpha_{\mathrm{PT}}$ varies from field to field. It is estimated as 1.8, 2.10 and 2.82 for the flood-, controlled drip- and reference drip-irrigated fields, respectively. It is clearly observed that the values related to drip irrigation are significantly greater than the values related field (sowing date, irrigation events, rainfall and fertilization) as well as uncertainties in retrieved $\alpha_{\text {PT. }}$ Two effects are likely to explain the highly variable and excessively high retrieved $\alpha_{\text {PT }}$ values over the drip irrigated site for the first few daily retrievals. First, it is reminded that $\alpha_{\mathrm{PT}}$ is retrieved for fc $>0.5$. When fc is slightly larger than 0.5 (that is on the first 
378 few retrieval days of the season), large uncertainties in retrieved $\alpha_{\mathrm{PT}}$ are expected because the 379 soil surface still plays a significant role in the observed LST. Little response is shown for the 380 first two months over the flood irrigation field, because the flux measurements over this site 381 started when wheat was already well developed (fc significantly larger than 0.5 ). Second, the 382 R3 site is surrounded by homogeneous irrigated wheat fields while the drip irrigated fields are surrounded by dryland, which potentially reinforces advection effects, leading to enhanced retrieved $\alpha_{\text {PT. }}$. Note that the retrieved $\alpha_{\text {PT }}$ values above 2 and near 0 are due to the uncertainties in LST-derived daily estimates, especially during the periods when wheat is partially covering the soil.

387 As explained above, a smoothing function is applied to reduce uncertainties in daily $\alpha_{\mathrm{PT}, \text {. The }}$ smoothing length (it is one parameter of the smoothing function) is set to $10 \%$ of the total time series, that is about 10-20 days. Such a smoothing procedure is justified by the fact that both biomass and root-zone soil moisture commonly change across the agricultural season with a characteristic time of 1 to 2 weeks (Albergel et al. 2008). Furthermore, Figure 5 clearly shows that the smoothing function removes all outliers while capturing significant patterns at the quasi daily scale. The smoothed $\alpha_{\mathrm{PT}}$ ranges from 0.03 to $1.22,0.17$ to 1.26 and 0.61 to 1.38 for the flood-, controlled drip- and reference drip-irrigated wheat, respectively. 

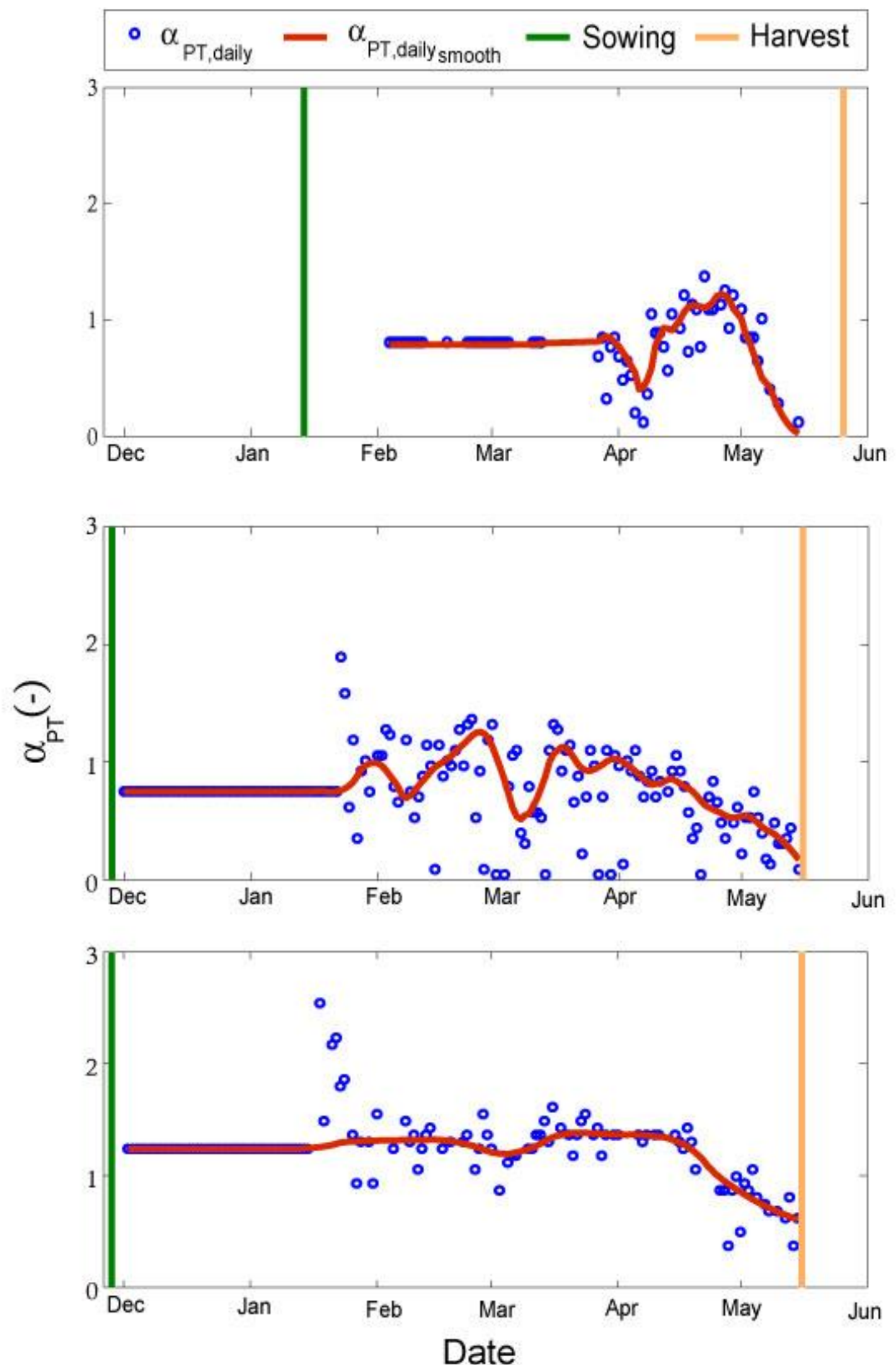

Figure 5.Time series of daily retrieved and smoothed $\alpha_{P T}$ for the (a) flood-, (b) controlled drip-and (c) reference dripirrigated wheat fields, separately (calibration step 2). 
400 The normalization in Equation (11) of smoothed $\alpha_{\mathrm{PT}}$ between its assumed minimum value (0) and smoothed maximum value makes the calibrated daily $\alpha_{\mathrm{PT}}$ range from 0 to $1.22,0$ to 1.26 and 0 to 1.38 for the flood-, controlled drip- and reference drip-irrigated fields, respectively. Time series of calibrated daily $\alpha_{\mathrm{PT}}$ are presented in Figure 6 superimposed with $\mathrm{f}_{\mathrm{c}}$ for comparison purposes. The maximum calibrated daily $\alpha_{\mathrm{PT}}$ is close to the theoretical value of 1.26 in each case. However, its temporal variability is found to be significant even during the growing stage of wheat. Calibrated daily $\alpha_{\mathrm{PT}}$ is more stable for the reference drip field than for both flood and controlled drip fields, with a relative change during the growing period of $8.08 \%$ compared to $26.94 \%$ and $22.66 \%$ for the other two fields, respectively. This result is consistent with the fact that the reference drip field had been irrigated according to the water needs estimated by the FAO-56 method while the other two fields (flood and controlled drip) had been under water deficit conditions for one or several periods during the growing stage. Note that the controlled-drip field has a special feature in terms of $\alpha_{\mathrm{PT}}$ daily dynamics. The maximum value is reached by the beginning of March, which is much earlier than the $\alpha_{\text {PT }}$ peak observed at the reference drip (around late April) and flood (beginning of May) fields, although wheat was sowed on the same date as reference drip field. It is suggested that the controlled dripirrigated wheat did not recover well from the first (relatively long) stress period from $22 / 02 / 2017$ to $06 / 03 / 2017$. The irrigation water supplied after mid-March was probably not sufficient for the wheat of controlled drip field to catch up with the reference drip-irrigated wheat, even if the amount of water used for irrigation after this period was approximately the same (about $166 \mathrm{~mm}$ ). 

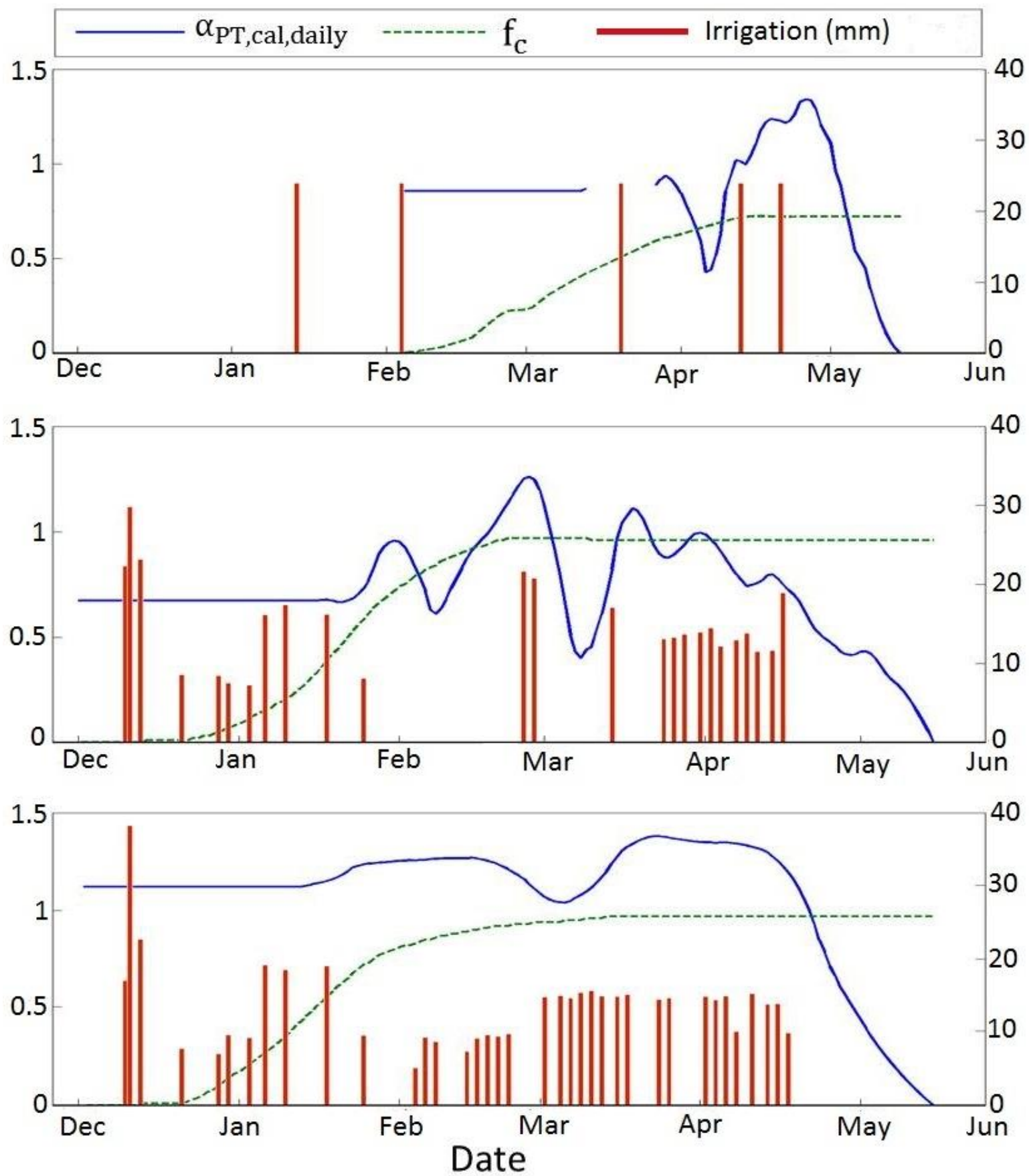

Figure 6.Time series of calibrated daily $\alpha_{P T}$, superimposed with $f c$ for the (a) flood-, (b) controlled drip-and (c) reference drip-irrigated wheat fields, separately. The red segments represent irrigations during the season.

\subsection{Interpretation of $\alpha_{\mathrm{PT}}$ variabilities}

$\alpha_{\mathrm{PT}}$ is expected to vary according to several factors including LAI, green fraction cover and soil water availability. In order to verify the consistency of the variations in daily retrieved $\alpha_{\mathrm{PT}}$, Figure 7 presents the time series of calibrated daily $\alpha_{\mathrm{PT}}$ superimposed with near-surface $(5-\mathrm{cm})$ soil moisture, deeper $(30-\mathrm{cm})$ soil moisture. It is reminded that the daily $\alpha_{\mathrm{PT}}$ for $\mathrm{f}_{\mathrm{c}}<0.5$ is set to the mean daily $\alpha_{\text {PT }}$ obtained for $\mathrm{f}_{\mathrm{c}}>0.5$ (see Figure 6 ). Therefore, the variability of $\alpha_{\mathrm{PT}}$ should be interpreted for $f_{c}>0.5$ only, that is from $f_{c}=0.5$ until harvest. Figure 7 illustrates the expected relationships between $\alpha_{\mathrm{PT}}$ and the water availability in the soil column. In each case, the $\alpha_{\mathrm{PT}}$ dynamics are driven by soil moisture variations. 
435 The qualitative analysis of $\alpha_{\mathrm{PT}}$ variability in relation to soil water availability indicates that $\alpha_{\mathrm{PT}}$ 436 cannot be considered as a constant. Large variations in this parameter are likely to occur during the agricultural season, especially under stress conditions. Water deficit may happen with flood irrigation when the frequency of water supplies (every 3 weeks on average over R3) is relatively low compared to the water demand under such semi-arid conditions. Indeed the water stress observed in the flood-irrigated wheat may be attributed to the increase in water depletion at the root zone through a removal of water by transpiration and percolation losses (Er-Raki et al., 2007). Water stress may also happen with drip when the technique is not appropriately implemented or by applying regulated deficit irrigation. 

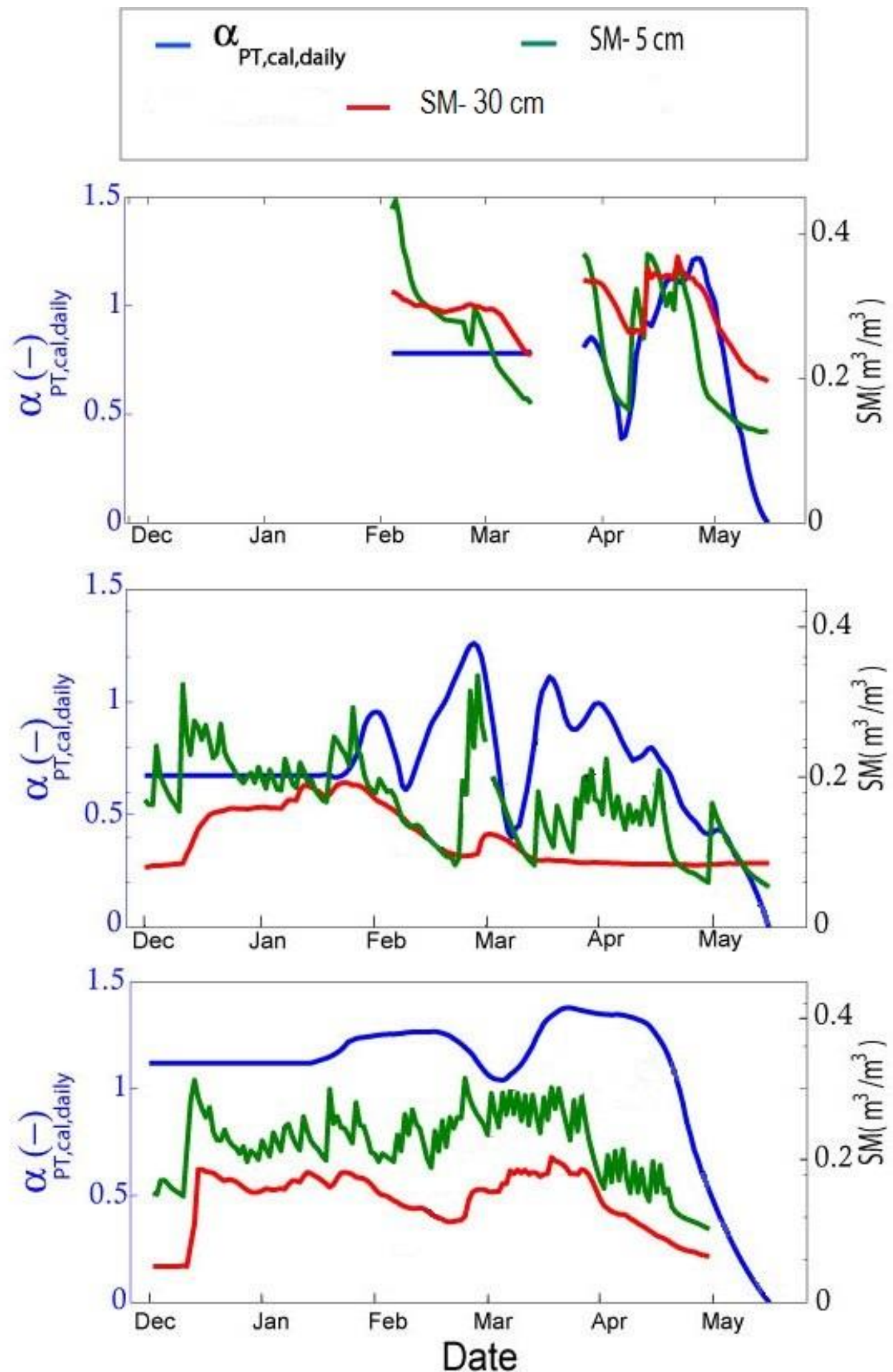
and (c) reference drip-irrigated fields, respectively. 


\subsection{Surface fluxes}

The ability of TSEB and TSEB-SM for partitioning the available energy into $\mathrm{H}$ and LE is assessed by forcing -in each case- $R_{n}$ and $G$ to their measured values. Note that the calibration of TSEB-SM is still undertaken using observed LST, SM and $f_{c}$ whereas the validation of TSEB and TSEB-SM model output is undertaken using EC measurements of $\mathrm{H}$ and LE. The metrics used to evaluate results comprise the determination coefficient $\left(\mathrm{R}^{2}\right)$, the root mean square error (RMSE) and the mean bias error (MBE) between simulated and observed fluxes.

Figure 8 plots simulated versus observed LE for the three sites separately. TSEB provides satisfying results for the flood site with a RMSE of $78 \mathrm{~W} / \mathrm{m}^{2}$ and a relative error (estimated as RMSE divided by mean observed LE) of $27 \%$. However, two notable features are observed for the other two (controlled and reference drip) sites: i) the LE simulated by TSEB never exceeds $500 \mathrm{~W} / \mathrm{m}^{2}$ over the entire growing season $\left(f_{c}>0.5\right)$ although observations reach $700 \mathrm{~W} / \mathrm{m}^{2}$ and ii) the overall MBE is about $29 \mathrm{~W} / \mathrm{m}^{2}$ and $66 \mathrm{~W} / \mathrm{m}^{2}$ for the controlled and reference drip field respectively, meaning that TSEB also overestimates LE in the lower ET range. To dig deeper, the performance of TSEB is now assessed by analyzing the metrics computed for three distinct periods of the agricultural season: the period for $f_{c} \leq 0.5$, for $f_{c}>0.5$ and the senescence stage. Note that the senescence period is defined herein as starting after the last peak observed on the calibrated daily $\alpha_{\text {PT }}$ (becomes remarkable after about one week) and finishing when green fraction cover becomes zero, which corresponds to the last date of the three time series. Hence the senescence starts on 27/04/2003, 19/04/2017 and 15/04/2017 for the flood-, controlled drip- and reference drip-irrigated field, respectively. A visual assessment of scatter plots in Figure 8 and the statistics presented in Table 1 clearly indicate that TSEB underestimates LE fluxes at around the maximum of ET (well developed crop before senescence) while it overestimates LE fluxes during senescence until harvest. The saturation of TSEB in the higher range of ET is due to the fixed maximum value for $\alpha_{\mathrm{PT}}$ (equal to 1.26). The structure of the model cannot accommodate large evaporative demand conditions and strong advective conditions (Song et al., 2016).

Both limitations identified in the TSEB formalism seem to be partly solved by the TSEB-SM approach. In particular, the LE simulated by TSEB-SM (Figure 8) is closer to the 1:1 line in each case $\left(\mathrm{f}_{\mathrm{c}} \leq 0.5\right.$ and $\mathrm{f}_{\mathrm{c}}>0.5$ and the senescence), providing a quite significant improvement for drip sites. The simulated LE does not saturate as it reaches $700 \mathrm{~W} / \mathrm{m}^{2}$ over the reference drip site. In fact, the retrieval of daily $\alpha_{\mathrm{PT}}$ values larger than the theoretical maximum 1.26 significantly improves ET estimates. Moreover, the overestimation of LE during the senescence stage is much reduced for TSEB-SM. It is suggested that the decrease in calibrated daily $\alpha_{\mathrm{PT}}$ integrates the drop in green vegetation fraction that takes place during senescence. 

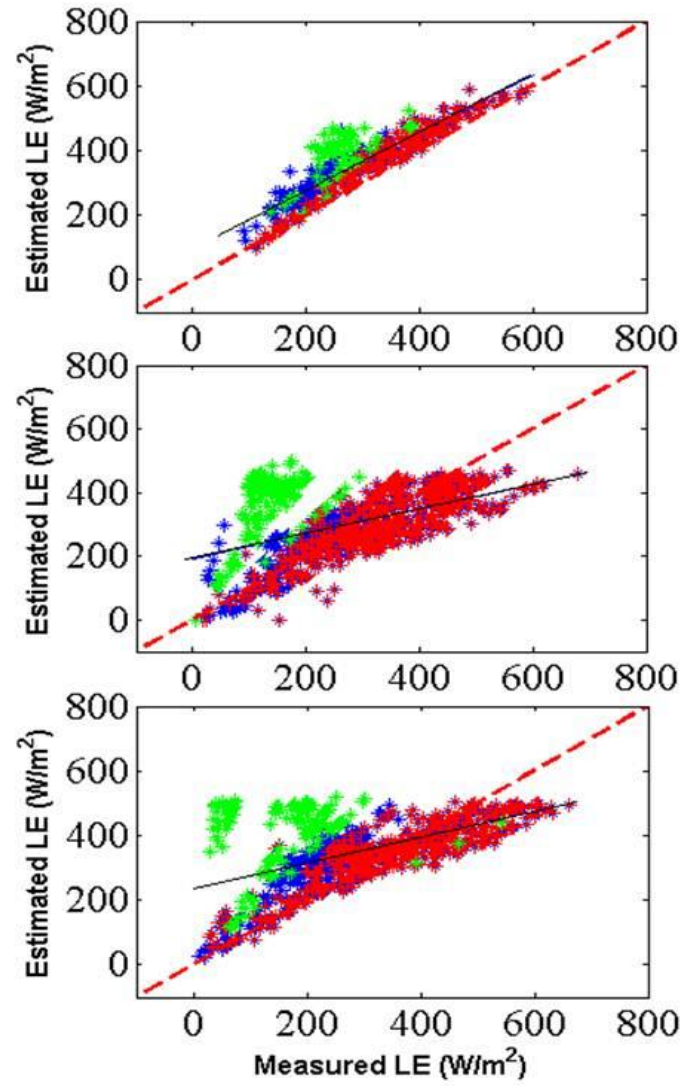

Classic TSEB
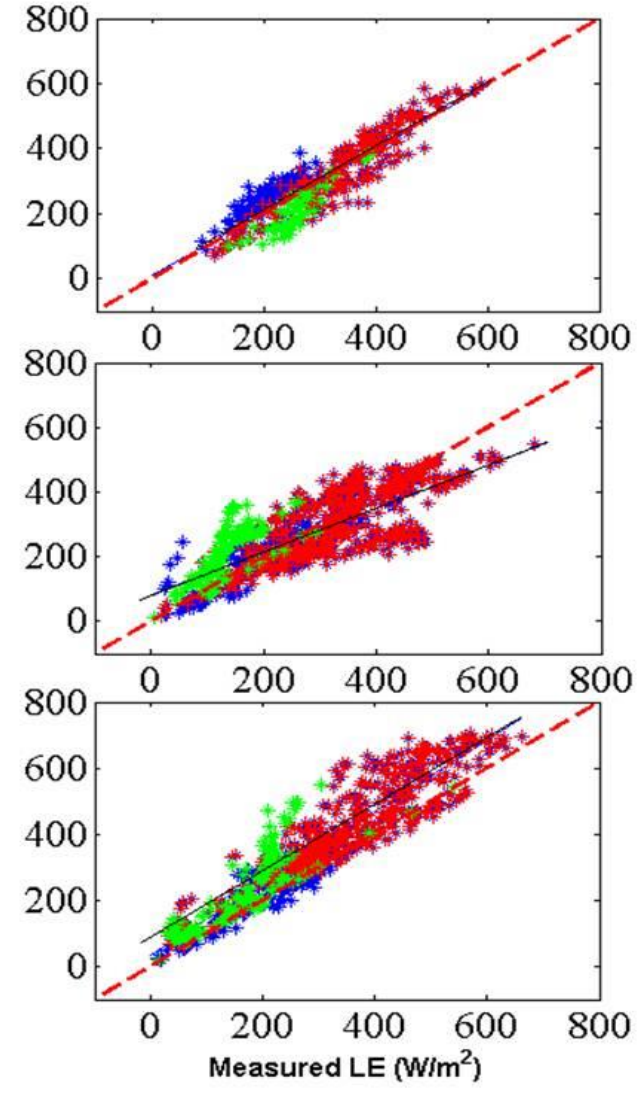

TSEB-SM

Figure 8.Scatterplot of simulated versus observed LE for the (top) food-, (middle) controlled drip- and (bottom) reference drip-irrigated fields and for (left) TSEB-SM and (right) TSEB models, respectively.

The comparison between TSEB and TSEB-SM is continued by plotting simulated versus observed $\mathrm{H}$ for each site in Figure 9. Consistent with previous results obtained for LE, the calibration strategy within TSEB-SM provides in general a significantly improved RMSE compared to the original TSEB. The RMSE is $49 \mathrm{~W} / \mathrm{m}^{2}$ instead of $73 \mathrm{~W} / \mathrm{m}^{2}, 78 \mathrm{~W} / \mathrm{m}^{2}$ instead of $78 \mathrm{~W} / \mathrm{m}^{2}$ and $119 \mathrm{~W} / \mathrm{m}^{2}$ instead of $128 \mathrm{~W} / \mathrm{m}^{2}$ for the flood-, controlled drip- and reference drip-irrigated field respectively. The determination coefficient between simulated and observed $\mathrm{H}$ is significantly improved from 0.61 to 0.67 , from 0.37 to 0.75 and from 0.29 to 0.82 , respectively when including calibrated parameters to TSEB-SM.

One can observe that the slope of the linear regression between TSEB and in situ $\mathrm{H}$ is very low in all cases. The modeled $\mathrm{H}$ does not seem to be sensitive enough to changes in surface and atmospheric conditions during all three periods $\left(\mathrm{f}_{\mathrm{c}} \leq 0.5, \mathrm{f}_{\mathrm{c}}>0.5\right.$ and senescence). 


\begin{tabular}{|ccc|}
$* \mathrm{fc}<0.5$ & + Growing $(\mathrm{fc}>0.5) \quad *$ Senescence \\
-- & Line(1:1) $\quad$ Regression line \\
\hline
\end{tabular}
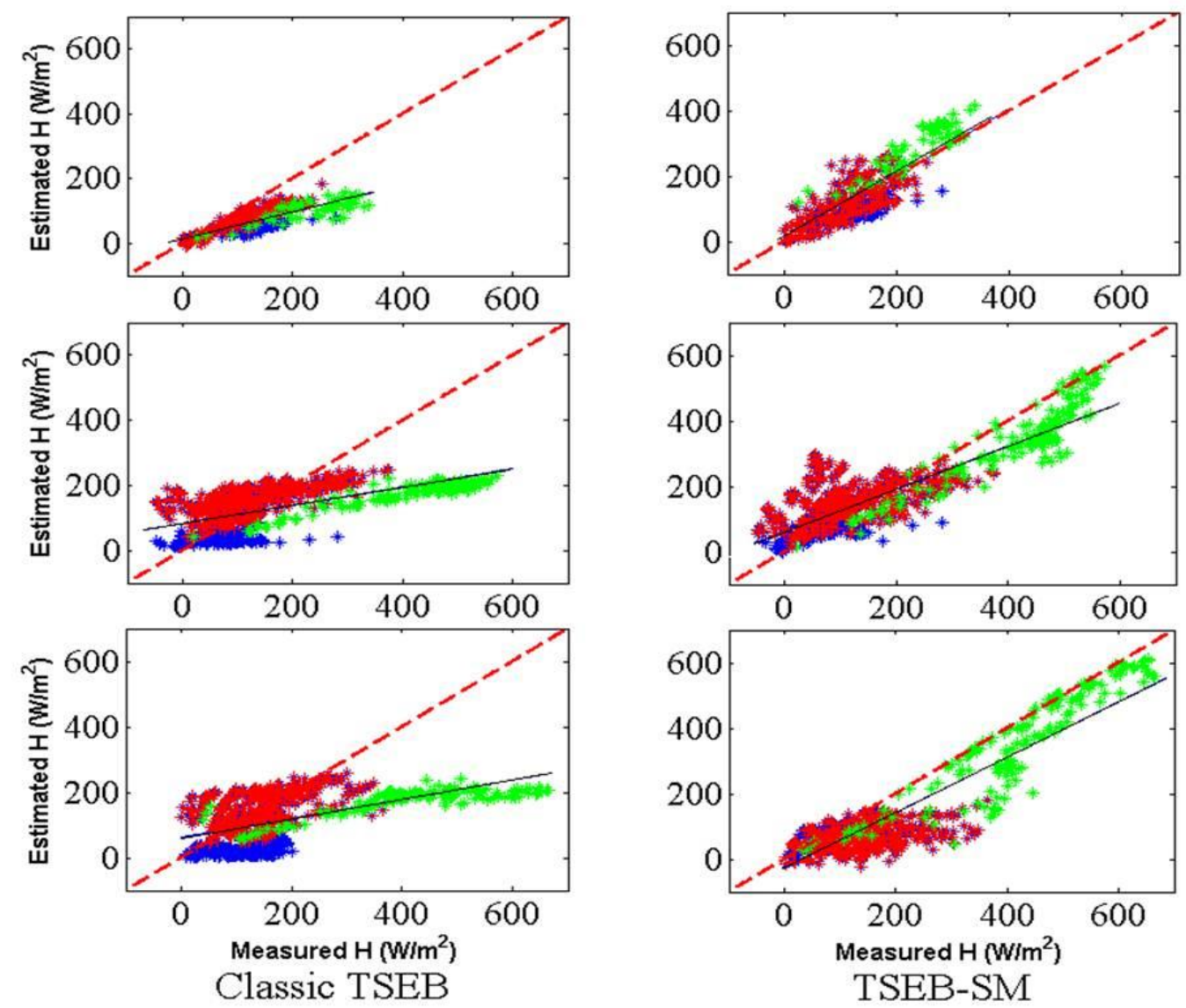

Figure 9.Scatterplot of simulated versus observed $H$ for the (top) food-, (middle) controlled drip- and (bottom) reference drip-irrigated fields and for (right) TSEB and (left) TSEB-SM model, respectively.

Tableau 1:Error statistics (RMSE, $\mathrm{R}^{2}$ and MBE) between modeled and measured sensible and latent heat fluxes for the flood, controlled drip- and reference drip-irrigated fields, and for TSEB and TSEB$\mathrm{SM}$ model, separately ( $\mathrm{Rn}$ and $\mathrm{G}$ are forced to their measured value

\begin{tabular}{|c|c|c|c|c|c|c|c|}
\hline & & \multicolumn{3}{|c|}{ TSEB-SM } & \multicolumn{3}{|c|}{ TSEB } \\
\hline & & $\begin{array}{l}\text { RMSE } \\
\left(\mathrm{W} / \mathrm{m}^{2}\right)\end{array}$ & $\begin{array}{l}\mathrm{R}^{2} \\
(-)\end{array}$ & $\begin{array}{c}\mathrm{MBE} \\
\left(\mathrm{W} / \mathrm{m}^{2}\right)\end{array}$ & $\begin{array}{l}\text { RMSE } \\
\left(\mathrm{W} / \mathrm{m}^{2}\right)\end{array}$ & $\begin{array}{l}\mathrm{R}^{2} \\
(-)\end{array}$ & $\begin{array}{c}\mathrm{MBE} \\
\left(\mathrm{W} / \mathrm{m}^{2}\right)\end{array}$ \\
\hline \multirow{3}{*}{$\begin{array}{l}\text { Latent } \\
\text { heat flux } \\
\text { (LE) }\end{array}$} & Flood & 49 & 0.79 & -4 & 78 & 0.79 & 66 \\
\hline & $\begin{array}{c}\text { Controlled } \\
\text { drip }\end{array}$ & 73 & 0.64 & -6 & 119 & 0.22 & 29 \\
\hline & $\begin{array}{c}\text { Reference } \\
\text { drip }\end{array}$ & 78 & 0.86 & 56 & 128 & 0.28 & 66 \\
\hline \multirow{3}{*}{$\begin{array}{c}\text { Sensible } \\
\text { heat flux } \\
(\mathrm{H})\end{array}$} & Flood & 49 & 0.67 & 4 & 78 & 0.61 & -66 \\
\hline & $\begin{array}{c}\text { Controlled } \\
\text { drip }\end{array}$ & 73 & 0.75 & 7 & 119 & 0.37 & -29 \\
\hline & $\begin{array}{c}\text { Reference } \\
\text { drip }\end{array}$ & 78 & 0.82 & -56 & 128 & 0.29 & -66 \\
\hline
\end{tabular}


The intercomparison between TSEB and TSEB-SM is finally undertaken by simulating the available energy, instead of forcing $\mathrm{Rn}$ and $\mathrm{G}$ to their measured values as in Table 1 . Table 2 reports the error statistics for the four energy fluxes separately. The larger discrepancies for LE estimated from TSEB-SM model in this case is likely due to greater scatter between modeled and measured Rn, which is related to the difference between simulated and observed LST. Note also that the determination coefficient between simulated and measured $\mathrm{G}$ is about $0.4-0.5$ for both TSEB and TSEB-SM and all three sites. This is linked in part to the relatively small magnitude and range in the observed values combined with the simplicity of the approach used to estimate G. Overall, the simulations of LE and $\mathrm{H}$ when modeling $\mathrm{Rn}$ and $\mathrm{G}$ are fully consistent with those obtained when forcing $\mathrm{Rn}$ and $\mathrm{G}$ to their measured values. TSEB-SM still provides superior results to TSEB in terms of RMSE, $\mathrm{R}^{2}$ and MBE between simulated and observed fluxes. Especially the sensible heat flux is significantly improved in all cases.

Tableau 2:Error statistics (RMSE. $\mathrm{R}^{2}$ and MBE) between modeled and measured net radiation, conductive flux, and sensible and latent heat fluxes for the flood, controlled drip- and reference dripirrigated fields, and for TSEB and TSEB-SM model, separately.

\begin{tabular}{|c|c|c|c|c|c|c|c|}
\hline & & \multicolumn{3}{|c|}{ TSEB-SM } & \multicolumn{3}{|c|}{ TSEB } \\
\hline & & $\begin{array}{l}\text { RMSE } \\
\left(\mathrm{W} / \mathrm{m}^{2}\right)\end{array}$ & $\begin{array}{l}\mathrm{R}^{2} \\
(-)\end{array}$ & $\begin{array}{c}\mathrm{MBE} \\
\left(\mathrm{W} / \mathrm{m}^{2}\right)\end{array}$ & $\begin{array}{l}\text { RMSE } \\
\left(\mathrm{W} / \mathrm{m}^{2}\right)\end{array}$ & $\begin{array}{l}R^{2} \\
(-)\end{array}$ & $\begin{array}{c}\mathrm{MBE} \\
\left(\mathrm{W} / \mathrm{m}^{2}\right)\end{array}$ \\
\hline \multirow{3}{*}{$\begin{array}{l}\text { Net } \\
\text { radiation } \\
(\mathrm{Rn})\end{array}$} & Flood & 31 & 0.98 & -25 & 18 & 0.99 & -17 \\
\hline & $\begin{array}{l}\text { Controlled } \\
\text { drip }\end{array}$ & 27 & 0.98 & -10 & 16 & 0.99 & 1 \\
\hline & $\begin{array}{l}\text { Reference } \\
\text { drip }\end{array}$ & 50 & 0.95 & -32 & 9 & 0.99 & 1 \\
\hline \multirow{3}{*}{$\begin{array}{l}\text { Conductif } \\
\text { flux }(\mathrm{G})\end{array}$} & Flood & 23 & 0.41 & 2 & 22 & 0.43 & 1 \\
\hline & $\begin{array}{l}\text { Controlled } \\
\text { drip }\end{array}$ & 20 & 0.5 & 9 & 25 & 0.48 & 12 \\
\hline & $\begin{array}{c}\text { Reference } \\
\text { drip }\end{array}$ & 14 & 0.39 & 14 & 30 & 0.38 & 26 \\
\hline \multirow[b]{2}{*}{$\begin{array}{c}\text { Sensible } \\
\text { heat flux } \\
(\mathrm{H})\end{array}$} & Flood & 27 & 0.66 & 34 & 78 & 0.61 & -67 \\
\hline & $\begin{array}{l}\text { Controlled } \\
\text { drip }\end{array}$ & 61 & 0.82 & 8 & 118 & 0.38 & -28 \\
\hline
\end{tabular}


Figure 10. Scatterplot of observed $H+L E$ versus observed Rn-G (left), corrected $H$ versus observed $H$ (center) and corrected LE versus observed LE (right) the food-(top), controlled (middle) and reference drip-irrigated (bottom) fields respectively.
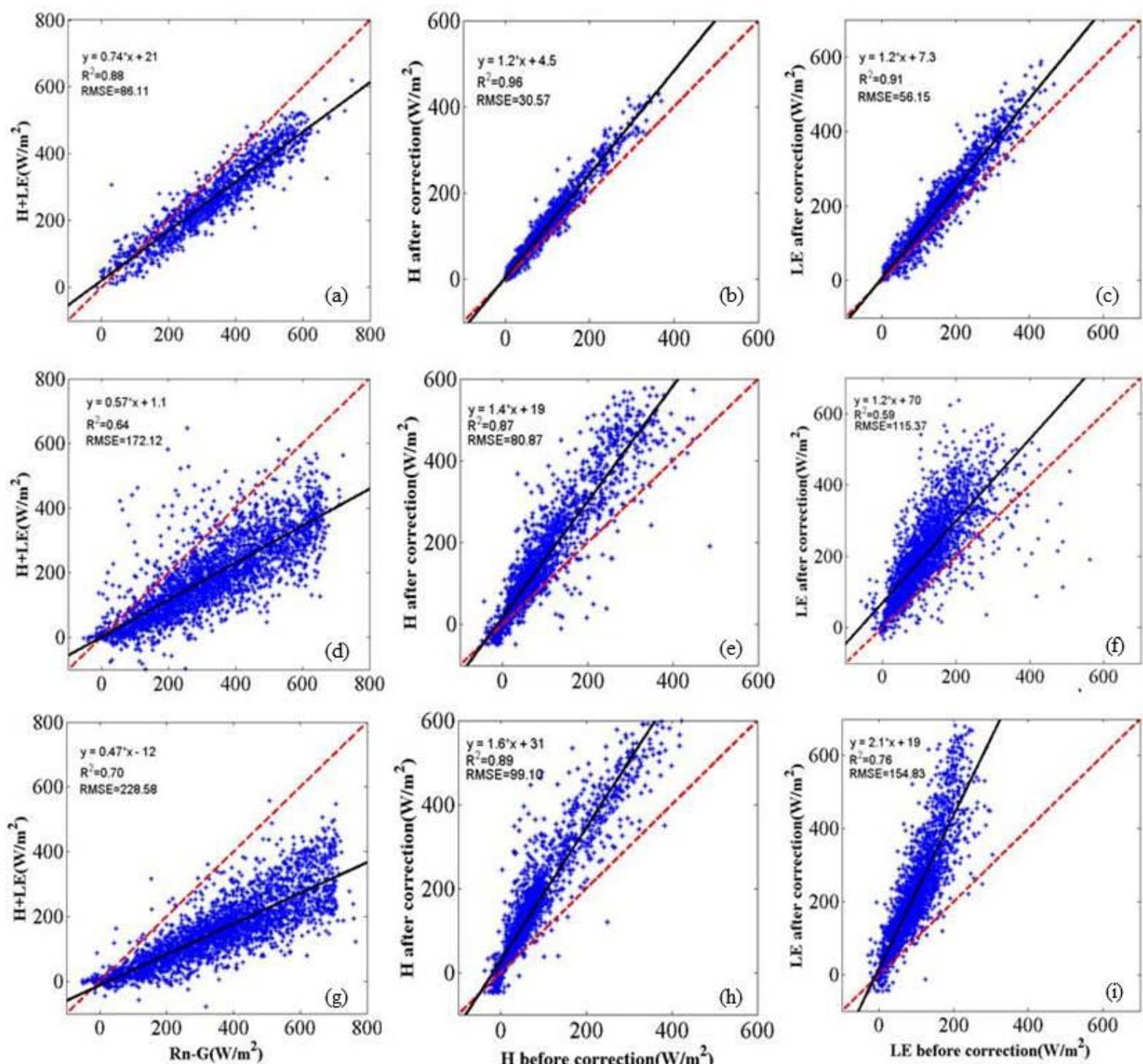

\section{Conclusions}

A new evapotranspiration model named TSEB-SM is derived from the TSEB formalism by explicitly representing soil evaporation using a soil resistance. An innovative calibration approach is also developed to retrieve the main parameters of soil evaporation and plant transpiration via the soil resistance and $\alpha_{\mathrm{PT}}$ respectively. In practice the soil resistance parameters are retrieved at the seasonal time scale from SM and LST data with $\mathbf{f}_{\mathbf{c}} \leq \mathbf{0 . 5}$. While $\alpha_{\mathrm{PT}}$ is retrieved at the daily time scale from SM and LST data for $\mathbf{f}_{\mathbf{c}}>\mathbf{0 . 5}$. The performance of TSEB-SM and TSEB models is assessed in terms of LE and H partitioning using an in situ data set collected over 1 flood- and 2 drip-irrigated wheat fields.

542 The convergence of the iterative calibration procedure on $\left(a_{\text {rss }} . b_{\text {rss }}\right)$ and $\alpha_{\text {PT }}$ is successfully tested when all three parameters are estimated at the seasonal time scale, as well as when 
considering a daily variability of $\alpha_{\mathrm{PT}}$. The maximum calibrated daily $\alpha_{\mathrm{PT}}$ is close to the theoretical value of 1.26 for all three sites. However its temporal variability is found to be significant even during the growing stage of wheat. A qualitative analysis of $\alpha_{\mathrm{PT}}$ variabilities in relation to soil moisture at $5 \mathrm{~cm}$ and $30 \mathrm{~cm}$ depth and to VWC indicates that $\alpha_{\mathrm{PT}}$ cannot be considered as a constant in the conditions of the experiments. Large deviations about the 1.26 value are likely to occur during the agricultural season especially under dry, water deficit and advective conditions.

In terms of flux estimates, TSEB provides satisfying results for the flood site but not for the other two (controlled and reference drip) sites. The saturation of TSEB in the higher range of ET is due to the fixed maximum value for $\alpha_{\mathrm{PT}}$ (equal to 1.26). Moreover, the overestimation of LE by TSEB during senescence is associated with a very low sensitivity of simulated $\mathrm{H}$ to any surface/atmospheric conditions. Both limitations identified in the TSEB formalism seem to be partly solved by the TSEB-SM approach with a slope of the linear regression between simulated and observed LE/H much closer to 1 in all cases. Such an evapotranspiration model simultaneously constrained by LST, $\mathrm{f}_{\mathrm{c}}$ and $\mathrm{SM}$ seems to respond robustly in terms of LE/H partitioning for wheat crops under the conditions of the experiments. However, the calibrated daily $\alpha_{\text {PT }}$ needed to be i) smoothed to reduce random uncertainties and ii) normalized between its two extreme values since the 0 value was not necessarily reached at harvest. In the real application the use of NDVI as a green vegetation index would provide complementary information to constrain even more the drop in the retrieved "effective $\alpha_{\mathrm{PT}}$ " during senescence. Further efforts should be made to investigate the variability of $\alpha_{\mathrm{PT}}$ at the daily and finer time scales and to relate its variations to variables other than biomass and soil water availability. Reciprocally, the retrieved $\alpha_{\mathrm{PT}}$ could serve as a basis for deriving a proxy for root zone soil moisture and crop water needs. Last but not least estimates of SM are needed at the crop field scale. Those data may be provided by satellite microwave data disaggregated at medium to high spatial resolution (Merlin et al., 2013; Molero et al., 2016). Especially, the L4DIS processor (Merlin et al., 2012; Molero et al., 2016) provides $1 \mathrm{~km}$ resolution SM data on a routine basis from $40 \mathrm{~km}$ resolution Soil Moisture and Ocean Salinity (SMOS) and $1 \mathrm{~km}$ resolution MODIS (Moderate resolution Imaging Spectroradiometer) data. Such a highresolution SM product would be fully compatible with future implementations of TSEB-SM over large areas.

\section{Acknowledgments}

Initial set up and maintenance of the field instrumentation (R3 and Chichawa) are funded by the Joint International Laboratory TREMA http://trema.ucam.ac.ma. This study was partly supported by the European Commission Horizon 2020 Programme for Research and Innovation (H2020) in the context of the Marie Sklodowska-Curie Research and Innovation Staff Exchange (RISE) action (REC project. grant agreement no: 645642) and the French Agence Nationale de la Recherche (MIXMOD-E project. ANR-13-JS06-003-01). Additional funding was provided by the ANR-AMETHYST project (ANR-12-TMED-0006-01). The ARTS fellowship program from Institut de Recherche pour le Développement (IRD) is fully acknowledged.

\section{References}

Agam, N., Kustas, W. P., Anderson, M. C., Norman, J. M., Colaizzi, P. D., Howell, T. A., ... $\&$ Wilson, T. B. (2010). Application of the Priestley-Taylor approach in a two-source surface energy balance model. Journal of Hydrometeorology, 11(1), 185-198. 
Ai, Z., \& Yang, Y. (2016). Modification and Validation of Priestley-Taylor Model for Estimating Cotton Evapotranspiration under Plastic Mulch Condition. Journal of Hydrometeorology, 17(4), 1281-1293.

Albergel, C., Rüdiger, C., Pellarin, T., Calvet, J. C., Fritz, N., Froissard, F., ... \& Martin, E. (2008). From near-surface to root-zone soil moisture using an exponential filter: an assessment of the method based on in-situ observations and model simulations. Hydrology and Earth System Sciences Discussions, 12, 1323-1337.

Allen, R. G., Pereira, L. S., Raes, D., \& Smith, M. (1998). Crop evapotranspiration-Guidelines for computing crop water requirements-FAO Irrigation and drainage paper 56. FAO, Rome, 300(9), D05109.

Allen, R. G. (2000). Using the FAO-56 dual crop coefficient method over an irrigated region as part of an evapotranspiration intercomparison study. Journal of Hydrology, 229(1), $27-41$.

Allen, R. G., Pereira, L. S., Howell, T. A., \& Jensen, M. E. (2011). Evapotranspiration information reporting: I. Factors governing measurement accuracy. Agricultural Water Management, 98(6), 899-920.

Anderson, M. C., Norman, J. M., Mecikalski, J. R., Otkin, J. A., \& Kustas, W. P. (2007). A climatological study of evapotranspiration and moisture stress across the continental United States based on thermal remote sensing: 1. Model formulation. Journal of Geophysical Research: Atmospheres, 112(D10).

Bindlish, R., Kustas, W. P., French, A. N., Diak, G. R., \& Mecikalski, J. R. (2001). Influence of near-surface soil moisture on regional scale heat fluxes: Model results using microwave remote sensing data from SGP97. IEEE transactions on geoscience and remote sensing, 39(8), 1719-1728.

Brutsaert, W., (1982). Evaporation Into The Atmosphere. Reidel, Dordrecht, 299 pp.

Chanzy, A., \& Bruckler, L. (1993). Significance of soil surface moisture with respect to daily bare soil evaporation. Water Resources Research, 29(4), 1113-1125.

Chehbouni, A., Escadafal, R., Duchemin, B., Boulet, G., Simonneaux, V., Dedieu, G., ... \& Sobrino, J. (2008). An integrated modelling and remote sensing approach for hydrological study in arid and semi-arid regions: The SUDMED Programme. International Journal of Remote Sensing, 29(17-18), 5161-5181.

Chirouze, J., Boulet, G., Jarlan, L., Fieuzal, R., Rodriguez, J.C., Ezzahar, J., Er-Raki, S., Bigeard, G., Merlin, O., Garatuza-Payan, J., Watts, C., Chehbouni, G., 2014. Intercomparison of four remote-sensing-based energy balance methods to retrieve surface evapotranspiration and water stress of irrigated fields in semi-arid climate. Hydrol. Earth Syst. Sci. 18, 1165-1188.

Choudhury, B.J., Idso, S., \& Reginato R. (1987). Analysis of an empirical model for soil heat flux under a growing wheat crop for estimating evaporation by an infrared-temperature based energy balance equation. Agricultural and Forest Meteorology, 39(4), 283-297.

Colaizzi, P. D., Evett, S. R., Howell, T. A., Gowda, P. H., O’Shaughnessy, S. A., Tolk, J. A., Kustas, W. P., \& Anderson, M. C.(2012). Two-source energy balance model: Rrefinements and lysimeter tests in the Southern High Plains. Trans. ASABE, 55(2), 551-562. 
Colaizzi, P. D., Agam, N., Tolk, J. A., Evett, S. R., Howell, T. A., Gowda, P. H., ... \& Anderson, M. C. (2014). Two source energy balance model to calculate E, T, and ET: Comparison of Priestley-Taylor and Penman-Monteith formulations and two time scaling methods. Trans. Asabe, 57(2), 479-498.

Dai Yongjiu and Zeng Qingcun. 1997. A land surface model (IAP94) for climate studies part I: Formulation and validation in off-line experiments. Advances in Atmospheric Sciences, 14, 433-460.

Davies, J. A., \& Allen, C. D. (1973). Equilibrium, potential and actual evaporation from cropped surfaces in southern Ontario. Journal of Applied Meteorology, 12(4), 649-657.

De Bruin, H. A. R. (1983). A model for the Priestley-Taylor parameter $\alpha$. Journal of climate and applied meteorology, 22(4), 572-578.

Diarra A., Jarlan L., Er-Raki S., Le Page M., Aouade G., Tavernier A., Boulet G, Ezzahar J., Merlin O., \& Khabba S. (2017). Performance of the two-source energy budget (TSEB) model for the monitoring of evapotranspiration over irrigated annual crops in North Africa, submitted to Agriculture water management.

Eichinger. W. E., Parlange. M. B., \& Stricker. H. (1996). On the concept of equilibrium evaporation and the value of the priestley-taylor coefficient. Water Resources Research. 32(1). 161-164.

Er-Raki, S., Chehbouni, A., Guemouria, N., Duchemin, B., Ezzahar, J., Hadria, R. (2007). Combining FAO-56 model and ground-based remote sensing to estimate water consumptions of wheat crops in a semi-arid region. Agricultural Water Management, $87,41-54$.

Er-Raki, S., Chehbouni, A., Khabba, S., Simonneaux, V., Jarlan,L., Ouldbba, A., Rodriguez, J.C., Allen, R. (2010). Assessment of reference evapotranspiration methods in semiarid regions: Can weather forecast data be used as alternate of ground meteorological parameters? Journal of Arid Environments. 74, 1587-1596.

Eichinger, W. E., Parlange, M. B., \& Stricker, H. (1996). On the concept of equilibrium evaporation and the value of the priestley-taylor coefficient. Water Resources Research, 32(1), 161-164.

Ershadi, A., McCabe, M. F., Evans, J. P., Chaney, N. W., \& Wood, E. F. (2014). Multi-site evaluation of terrestrial evaporation models using FLUXNET data. Agricultural and Forest Meteorology, 187, 46-61.

Ezzahar, J., Chehbouni, A., Er-Raki, S., \& Hanich, L. (2009). Combining a large aperture scintillometer and estimates of available energy to derive evapotranspiration over several agricultural fields in a semi-arid region, Plant Biosystems,143(1), 209-221

Federer, C. A., Vörösmarty, C., \& Fekete, B. (2003). Sensitivity of annual evaporation to soil and root properties in two models of contrasting complexity. Journal of Hydrometeorology, 4(6), 1276-1290.

Fisher, J. B., Tu, K. P., \& Baldocchi, D. D. (2008). Global estimates of the land-atmosphere water flux based on monthly AVHRR and ISLSCP-II data, validated at 16 FLUXNET sites. Remote Sensing of Environment, 112(3), 901-919.

French, A. N., Hunsaker, D. J., \& Thorp, K. R. (2015). Remote sensing of evapotranspiration over cotton using the TSEB and METRIC energy balance models. Remote Sens. Environ., 158, 281-294. 
Gentine, P., Entekhabi, D., Chehbouni, A., Boulet, G., and Duchemin, B. (2007): Analysis of evaporative fraction diurnal behaviour. Agric. For. Meteor., 143, 13-29.

Gharsallah O., Facchi A., Gandolf C. (2013). Comparison of six evapotranspiration models for a surface irrigated maize agro-ecosystem in Northern Italy. Agricultural Water Management, 130, 119-130

Gokmen, M., Vekerdy, Z., Verhoef, A., Verhoef, W., Batelaan, O., \& Van der Tol, C. (2012). Integration of soil moisture in SEBS for improving evapotranspiration estimation under water stress conditions. Remote Sensing of Environment, 121, 261-274.

Hain, C. R., Mecikalski, J. R., \& Anderson, M. C. (2009). Retrieval of an available water-based soil moisture proxy from thermal infrared remote sensing. Part I: Methodology and validation. Journal of Hydrometeorology, 10(3), 665-683.

Jarlan, L., Khabba, S., Er-Raki, S., Le Page, M., Hanich, L., Fakir, Y., ... \& Kharrou, M. H. (2015). Remote sensing of water resources in semi-arid Mediterranean areas: The joint international laboratory TREMA. International Journal of Remote Sensing, 36(19-20), 4879-4917.

Jiang, L., \& Islam, S. (2001). Estimation of surface evaporation map over southern Great Plains using remote sensing data. Water resources research, 37(2), 329-340.

Jin, Y., Randerson, J. T., \& Goulden, M. L. (2011). Continental-scale net radiation and evapotranspiration estimated using MODIS satellite observations. Remote Sensing of Environment, 115(9), 2302-2319.

Jung, M., Reichstein, M., Ciais, P., Seneviratne, S. I., Sheffield, J., Goulden, M. L., ... \& Dolman, A. J. (2010). Recent decline in the global land evapotranspiration trend due to limited moisture supply. Nature, 467(7318), 951-954.

Jury, W. A., \& Tanner, C. B. (1975). Advection modification of the Priestley and Taylor evapotranspiration formula. Agronomy Journal, 67(6), 840-842.

Kalma J.D., McVicar T.R., and McCabe M.F. (2008). Estimating Land Surface Evaporation: A Review of Methods Using Remotely Sensed Surface Temperature Data. Surv Geophys ,29, 421-469.

Khabba, S., Duchemin B., Hadria, R., Ezzahar J., Chehbouni A., Lahrouni A., Hanich L.(2009). Evaluation of digital hemispherical photography and plant canopy analyser for measuring Vegetation area index of orange orchards. Journal of Agronomy, 8(2), 6772.

Kustas, W.P., \& Norman, J.M. (1997). A two-source approach for estimating turbulent fluxes using multiple angle thermal infrared observations. Water resources research, 33(6),1495-1508.

Kustas, W. P., Zhan, X., \& Schmugge, T. J. (1998). Combining optical and microwave remote sensing for mapping energy fluxes in a semiarid watershed. Remote Sensing of Environment, 64(2), 116-131.

Kustas, W. P., Zhan, X., \& Jackson, T. J. (1999). Mapping surface energy flux partitioning at large scales with optical and microwave remote sensing data from Washita'92. Water resources research, 35(1), 265-277. 
Kustas, W. P., \& Norman, J. M. (1999). Evaluation of soil and vegetation heat flux predictions using a simple two-source model with radiometric temperatures for partial canopy cover. Agricultural and Forest Meteorology, 94(1), 13-29

Kustas, W.P., Prueger, J.H., Hatfield, J.L., Ramalingam, H., \& Hipps, L.E. (2000). Variability in soil heat flux from a mesquite dune site. Agricultural and Forest Meteorology,103(1), 249-264.

Kustas, W. P., Bindlish, R., French, A. N., \& Schmugge, T. J. (2003). Comparison of energy balance modeling schemes using microwave-derived soil moisture and radiometric surface temperature. Water resources research, 39(2).

Lhomme, J. P., Boudhina, N., Masmoudi, M. M., and Chehbouni, A.(2015). Estimation of crop water requirements: extending the one-step approach to dual crop coefficients. Hydrol. Earth Syst. Sci. 19, 3287-3299.

Li, F., Kustas, W. P., Prueger, J. H., Neale, C. M., \& Jackson, T. J. (2005). Utility of remote sensing-based two-source energy balance model under low-and high-vegetation cover conditions. Journal of Hydrometeorology, 6(6), 878-891.

Li, F., Kustas, W. P., Anderson, M. C., Jackson, T. J., Bindlish, R., \& Prueger, J. H. (2006). Comparing the utility of microwave and thermal remote-sensing constraints in twosource energy balance modeling over an agricultural landscape. Remote sensing of environment, 101(3), 315-328.

Li, F., Crow, W. T., \& Kustas, W. P. (2010). Towards the estimation root-zone soil moisture via the simultaneous assimilation of thermal and microwave soil moisture retrievals. Advances in Water Resources, 33(2), 201-214.

Li, Y., Zhou, J., Wang, H., Li, D., Jin, R., Zhou, Y., \& Zhou, Q. (2015). Integrating soil moisture retrieved from L-band microwave radiation into an energy balance model to improve evapotranspiration estimation on the irrigated oases of arid regions in northwest China. Agricultural and Forest Meteorology, 214, 306-318.

Long, D., \& Singh, V. P. (2012). A two-source trapezoid model for evapotranspiration (TTME) from satellite imagery. Remote Sensing of Environment, 121, 370-388.

Martínez Pérez, J. Á., García-Galiano, S. G., Martin-Gorriz, B., \& Baille, A. (2017). SatelliteBased Method for Estimating the Spatial Distribution of Crop Evapotranspiration: Sensitivity to the Priestley-Taylor Coefficient. Remote Sensing, 9(6), 611.

McAneney, K. J., \& Itier, B. (1996). Operational limits to the Priestley-Taylor formula. Irrigation Science, 17(1), 37-43.

Merlin, O., Al Bitar, A., Rivalland, V., Béziat, P., Ceschia, E., \& Dedieu, G. (2011). An analytical model of evaporation efficiency for unsaturated soil surfaces with an arbitrary thickness. Journal of Applied Meteorology and Climatology, 50(2), 457-471.

Merlin, O., Rudiger, C., Al Bitar, A., Richaume, P., Walker, J. P., \& Kerr, Y. H. (2012). Disaggregation of SMOS soil moisture in Southeastern Australia. IEEE Transactions on Geoscience and Remote Sensing, 50(5), 1556-1571. 
Merlin, O., Escorihuela, M. J., Mayoral, M. A., Hagolle, O., Al Bitar, A., \& Kerr, Y. (2013) Self-calibrated evaporation-based disaggregation of SMOS soil moisture: An evaluation study at $3 \mathrm{~km}$ and $100 \mathrm{~m}$ resolution in Catalunya, Spain. Remote sensing of environment, 130, 25-38.

Merlin, O., Chirouze, J., Olioso, A., Jarlan, L., Chehbouni, G., \& Boulet, G. (2014). An imagebased four-source surface energy balance model to estimate crop evapotranspiration from solar reflectance/thermal emission data (SEB-4S). Agricultural and Forest Meteorology, 184, 188-203.

Merlin, O., Stefan, V. G., Amazirh, A., Chanzy, A., Ceschia, E., Er-Raki, S., ... \& Beringer, J. (2016). Modeling soil evaporation efficiency in a range of soil and atmospheric conditions using a meta-analysis approach. Water Resources Research, 52(5), 36633684.

Merlin, O., Olivera-Guerra, L., Aït Hssaine, B., Amazirh, A., Rafi, Z., Ezzahar, J., Gentine, P., Khabba, S., Gascoin, S., Er-Raki, S., A phenomenological model of soil evaporative efficiency using readily available data, submitted to Agricultural and Forest Meteorology.

Molero, B., Merlin, O., Malbéteau, Y., Al Bitar, A., Cabot, F., Stefan, V., ... \& Jackson, T. J. (2016). SMOS disaggregated soil moisture product at $1 \mathrm{~km}$ resolution: Processor overview and first validation results. Remote Sensing of Environment, 180, 361-376.

Monteith, J. L. (1965, July). Evaporation and environment. In Symp. Soc. Exp. Biol , 19(4), 205-23.

Moran, M. S., Clarke, T. R., Inoue, Y., \& Vidal, A. (1994). Estimating crop water deficit using the relation between surface-air temperature and spectral vegetation index. Remote sensing of environment, 49(3), 246-263.

Mukammal, E. I., \& Neumann, H. H. (1977). Application of the Priestley-Taylor evaporation model to assess the influence of soil moisture on the evaporation from a large weighing lysimeter and class A pan. Boundary-Layer Meteorology, 12(2), 243-256.

Norman, J. M., Kustas, W. P., \& Humes, K. S. (1995). Two source approach for estimating soil and vegetation energy fluxes in observations of directional radiometric surface temperature. Agricultural and Forest Meteorology, 77(3), 263-293.

Oleson, K. W., Niu, G. Y., Yang, Z. L., Lawrence, D. M., Thornton, P. E., Lawrence, P. J., Stockli, R., Dickinson, R. E., Bonan, G. B., and Levis, S. (2008). Improvements to the Community Land Model and their impact on the hydrological cycle, J. Geophys. Res., 113, G01021, doi:10.1029/2007JG000563.

Passerat de Silans, A., 1986. Transferts de masse et de chaleur dans un sol stratifie soumis une excitation atmosphérique naturelle. Compara son modèle expérience. PhD Thesis, Institut National Polytechnique de Grenoble, France.

Pereira, A. R., \& Nova, N. A. V. (1992). Analysis of the Priestley-Taylor parameter. Agricultural and Forest Meteorology, 61(1-2), 1-9.

Pereira, A. R. (2004). The Priestley-Taylor parameter and the decoupling factor for estimating reference evapotranspiration. Agricultural and Forest Meteorology, 125(3), 305-313. 
Price, J. C. (1990). Using spatial context in satellite data to infer regional scale evapotranspiration. IEEE transactions on Geoscience and Remote Sensing, 28(5), 940948.

Priestley, C. H. B., \& Taylor, R. J. (1972). On the assessment of surface heat flux and evaporation using large-scale parameters. Monthly weather review, 100(2), 81-92.

Roerink, G. J., Su, Z., \& Menenti, M. (2000). S-SEBI: A simple remote sensing algorithm to estimate the surface energy balance. Physics and Chemistry of the Earth. Part B: Hydrology, Oceans and Atmosphere, 25(2), 147-157.

Sauer, T. J., Norman, J. M., Tanner, C. B., \& Wilson, T. B. (1995). Measurement of heat and vapor transfer at the soil surface beneath a maize canopy using source plates. Agricultural and Forest Meteorology, 75, 161-189.

Sellers, P. J., Heiser, M. D., \& Hall, F. G. (1992). Relations between surface conductance and spectral vegetation indices at intermediate $(100 \mathrm{~m} 2$ to $15 \mathrm{~km} 2)$ length scales. Journal of Geophysical Research, 97(D17), 19-033.

Song, L., Kustas, W. P., Liu, S., Colaizzi, P. D., Nieto, H., Xu, Z., ... \& Tolk, J. A. (2016). Applications of a thermal-based two-source energy balance model using PriestleyTaylor approach for surface temperature partitioning under advective conditions. Journal of Hydrology, 540, 574-587.

Su, Z. (2002). The Surface Energy Balance System (SEBS) for estimation of turbulent heat fluxes. Hydrology and Earth System Sciences, 6(1), 85-100.

Sun, J., Salvucci, G. D., \& Entekhabi, D. (2012). Estimates of evapotranspiration from MODIS and AMSR-E land surface temperature and moisture over the Southern Great Plains. Remote sensing of environment, 127, 44-59.

Timmermans, W.J., Kustas, W.P., Anderson, M.C., French, A.N. (2007). An intercomparison of the surface energy balance algorithm for land (SEBAL) and the two-source energy balance (TSEB) modeling schemes. Remote Sensing of Environment. 108, 369-384.

Twine, T.E., Kustas, W.P., Norman, J.M., Cook, D.R., \& Houser, P.R. (2000). Correctingeddycovariance flux underestimation over a grassland. Agricultural and Forest Meteorology, 103(3), 279-300.

Van de Griend, A. A., and Owe M. (1994). Bare soil surface resistance to evaporation by vapor diffusion under semiarid conditions, Water Resour. Res., 30(2), 181-188.

Van Dijk, A., Moene A. F., \& de Bruin H. A. R. (2004). The principles of surface flux physics: Theory. Practice and Description of the ECPACK Library, 99-100.

Wang, K., Li, Z., \& Cribb, M. (2006). Estimation of evaporative fraction from a combination of day and night land surface temperatures and NDVI: A new method to determine the Priestley-Taylor parameter. Remote Sensing of Environment, 102(3), 293-305.

Yao, Y., Liang, S., Li, X., Chen, J., Wang, K., Jia, K., ... \& Grünwald, T. (2015). A satellitebased hybrid algorithm to determine the Priestley-Taylor parameter for global terrestrial latent heat flux estimation across multiple biomes. Remote Sensing of Environment, 165, 216-233. 
839 Yao, Y., Liang, S., Yu, J., Zhao, S., Lin, Y., Jia, K., ... \& Wang, X. (2017). Differences in estimating terrestrial water flux from three satellite-based Priestley-Taylor algorithms. International Journal of Applied Earth Observation and 